\title{
An overview of the challenges of solar power integration in isolated industrial microgrids with reliability constraints
}

\author{
Authors details : \\ Louis Polleux ${ }^{1,2,}$, Gilles Guerassimoff ${ }^{1}$, Jean-Paul marmorat ${ }^{1}$, John Sandoval Moreno ${ }^{2}$, Thierry Schuhler ${ }^{2}$ \\ 1 Center for Applied Mathematics, Mines Paristech PSL, Sophia Antipolis, France \\ 2 Research \& Development, TotalEnergies, Paris, France
}

\begin{abstract}
Reducing carbon emissions and electricity costs in industry is a major challenge to ensure competitiveness and compliance with new climate policies. Photovoltaic power offers a promising solution but also brings considerable uncertainties and risks that may endanger the continuity and quality of supply. From an operational point of view, large-scale integration of solar power could result in unmet demand, electrical instabilities and equipment damage. The performance and lifetime of conventional fossil equipment are likely to be altered by repeated transient operations, making it necessary to adopt specific modeling tools. Control strategies and sizing methodologies must be adapted to account for the strong reliability constraint while dealing with significant production uncertainties. In addition, conventional mitigation technologies, such as storage and load flexibility, have limited potential in these applications and may result in high investments or penalties if they are not properly assessed. This study provides an overview of these challenges by providing a transversal analysis of the scientific literature from fossil engine thermodynamics to control system theory applied to industrial systems. The main characteristics of reliability-constrained microgrids are identified and a conceptual definition is proposed by analyzing state-of-the art studies of various industrial applications and taking oil-and gas microgrids as an enlightening example. Then follows a review of the challenges of accounting for dynamical behavior of fossil equipment, PV and storage systems, ending with the identification of several research gaps. Finally, applicable control strategies and sizing techniques are presented.
\end{abstract}

Keywords : Microgrids, Renewable integration, Industry, Power quality

\section{Highlights :}

- The concept of industrial microgrids is defined and existing applications are reviewed.

- The challenges of dynamical modeling of fossil generation and PV systems are presented.

- $\quad$ State-of-the-art relevant power control and energy management strategies are set out.

Word count : 9,909

List of abbreviations :

ASAI : Averagae Service Availability Index

ASUI : Average Service Unavailability Index

CAIDI : Customer Average Interruption Duration Index

CCGT : Combined cycle gas turbine

* Corresponding author details : louis.polleux@ mines-paristech.fr 
CFD: Computational fluid dynamics

DC: Direct Current

EENS : Expected Energy Not Supplied

EMS: Energy management system

GHG: Greenhouse gases

GHI : Global horizontal irradiance

GT : Gas turbine

HIL: Hardware in the loop

ICE : Internal combustion engine

IEA : International energy agency

ISO : International Organization for Standardization

LCOE: Levelized costs of electricity

LNG : Liquefied natural gas

LP: Linear programming

MG : Microgrid

MILP: Mixed integer linear programming

MPC: Model Predictive control

O\&G: Oil and gas

O\&M : Operation and maintenance

PV: Photovoltaic

R\&D: Research and development

TSO: Transmission system operator

VIGV : Variable inlet guide vane

WVM : Wavelet variability model

\section{Manuscript}

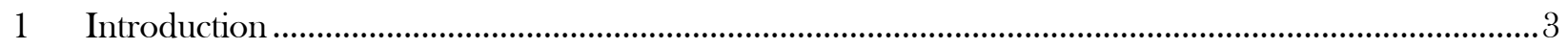

1.1 The concept of industrial off-grid microgrids .......................................................................

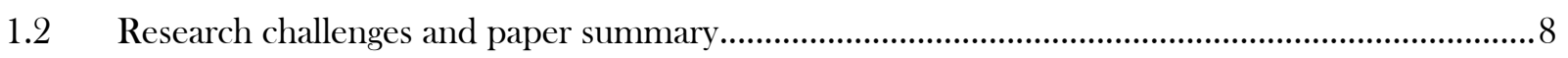




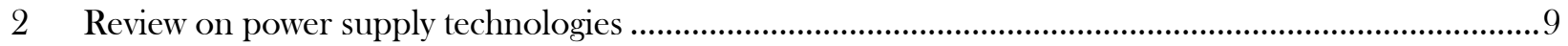

2.1 The challenge of solar-power variability ….....................................................................................

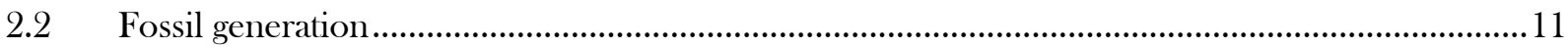

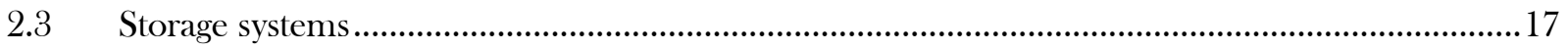

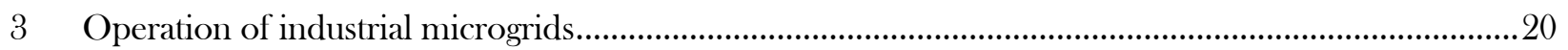

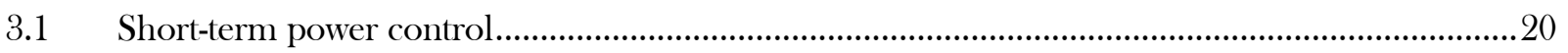

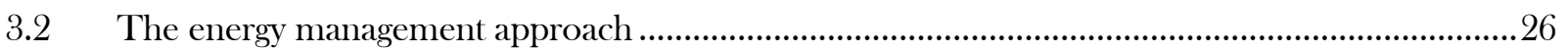

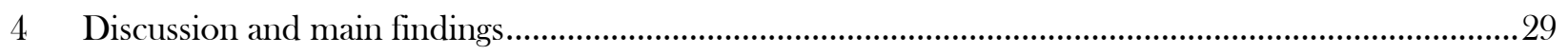

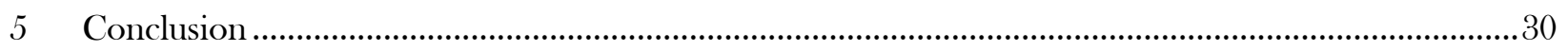

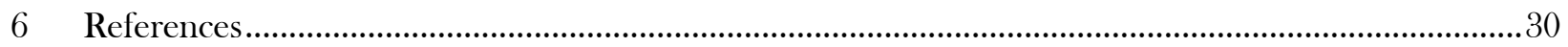

\section{Introduction}

The beginning of the 2020 decade, subject to a combination of climate change mitigation and poverty alleviation, faces the world with a double challenge that needs to be tackled as fast as possible [1], [2]. Establishing an efficient low-carbon industry is a priority to support socio-economic development while meeting Paris Agreement targets.

In 2016, the industry sector accounted for 36\% of global CO2 emissions, mainly due to its high energyintensive processes [3]. The IEA continues to highlight that power facilities operating with low-carbon electricity constitute one of the three main levers to achieve a sustainable transition [4].

Facilities located in developed countries can substantially reduce their GHG emissions using process electrification with green electricity purchase agreements [5]. However, in numerous applications, plants are either connected to an unreliable grid or totally isolated from it [6]. In these applications, microgrids will play a key role.

One of the main advantages of microgrids is undoubtably the ability to manage renewable energy resources as well as storage and conventional fossil generation to ensure the right trade-off between costs, reliability and sustainability [7], [8]. Microgrids now cover a wide variety of uses, from grid-connected systems able to sell and buy electricity depending on the market price, to robust and isolated systems ensuring continuous power for mining or military facilities. Examples of such systems can be found in [9] and [10].

Microgrid studies mainly focus on either investment planification or operational management with an optimization philosophy in order to find a compromise between three main objectives [11]: providing electricity at the lowest cost or carbon footprint possible; ensuring the safe supply of electricity to deliver all consumers at the required time; and guaranteeing the quality of supply at the delivery point.

This optimization paradigm is the cornerstone of a microgrid's performance, from early developments to the plant's real-time management, and must be able to handle phenomena that take place at various time-scales. The long-term planning (or sizing) of micro-grids involves several development steps and aims at finding the optimal architecture to optimize the plant in the long run (typically 20 years) [12]-[18]. Energy management aims at balancing energy flows between producers and consumers. Different strategies may be used to minimize the costs under constraints of reliability or environmental footprint. This is typically carried out within intervals of 10 minutes to several days [19]-[21]. Controlling power ensures good quality of supply and 
safe operation, and prevents large fluctuations and instabilities by balancing power flows in real time. This is generally assessed with a timescale from a few milliseconds to seconds [22]-[24].

Due to the relatively small size of microgrids compared to utility grids, their sensitivity to power fluctuations is significantly increased, with the result that developers now have to account for power dynamics, flexibility and production uncertainties [25], [26]. Since microgrids are local energy systems, technological choices may differ from one user case to another, such as commercial, residential, military or industrial plants. Unlike for commercial and residential applications, the literature only scantly covers industrial microgrids [27], [28]. However, specific constraints on industrial power systems modify the above-mentioned optimization paradigm and call for a deeper understanding of the dynamic behavior of their components, such as renewable systems and fossil generation. This brings considerable research challenges to the microgrid field involving numerous problematics, varying from classic control system theory to fossil generator thermodynamics and renewable resource signal treatment.

\subsection{The concept of industrial off-grid microgrids}

\subsubsection{General definition}

It is difficult to establish a proper definition, since needs, size and resources may substantially differ from one case to another. Based on a review of existing projects, studies and industrial surveys, it is possible to propose some general characteristics:

- $\quad$ Size: The installed power capacity or total load served generally exceeds several hundreds of kW (and $\mathrm{kWh}$ ) and often reaches several MW (and MWh).

- $\quad$ Types of consumer: Consumers are mainly operators of industrial equipment such as electric drivers for torque production, pumping and compression. The proportion of resistive load may be slightly lower than on the residential microgrid. The daily profile follows the production schedule and therefore differs significantly from a residential and tertiary load profile.

- Ownership and operation: The generating units and transmission system within the industrial microgrid can be financed, owned and operated by different entities, but assets are rarely separated or managed individually. Consuming equipment is considered as a single client.

Table 1 Examples of studies and projects focusing on industrial microgrids

\begin{tabular}{lcccccc}
\hline Reference & [29] & [30] & [31] & [32] & [33] & [34] \\
\hline Application & Mining & $\begin{array}{c}\text { Offshore } \\
\text { oil }\end{array}$ & Industry & Industry & $\begin{array}{c}\text { Water } \\
\text { treatment }\end{array}$ & $\begin{array}{c}\text { Manufacturi } \\
\text { ng }\end{array}$ \\
\hline Energy & Electricity & Electricity & $\begin{array}{c}\text { Heat/ } \\
\text { Electricit } \\
\mathrm{y}\end{array}$ & $\begin{array}{c}\text { Electrici } \\
\text { ty }\end{array}$ & Electricity & Electricity \\
\hline Power & $26 \mathrm{MW}$ & $40 \mathrm{MW}$ & $14 \mathrm{MW}$ & $\begin{array}{c}\text { MW- } \\
\text { scale }\end{array}$ & $3.2 \mathrm{MW}$ & $20-40 \mathrm{MW}$ \\
\hline On grid/ off grid & Off-grid & Off-grid & On-grid & $\begin{array}{c}\text { Not } \\
\text { specifie } \\
\text { d }\end{array}$ & On grid & On grid \\
$\begin{array}{l}\text { Renewable } \\
\text { resource }\end{array}$ & Solar & Wind & - & $\begin{array}{c}\text { Wind - Wind Solar } \\
\text { Solar }\end{array}$ & Wind Solar \\
\hline
\end{tabular}




\begin{tabular}{lcccccc}
\hline Fossil generation & Diesel & CCGT $^{\dagger}$ & $\begin{array}{c}\text { Not } \\
\text { specified }\end{array}$ & Diesel & Diesel & - \\
\hline Storage & - & - & - & - & - & Yes \\
\hline Comment & $\begin{array}{c}\text { Installed } \\
\text { plant }\end{array}$ & Study & Study & Study & Study & Study \\
\hline
\end{tabular}

\subsubsection{Reliability as a watchword for planning and operation}

It is needless to say that ensuring the continuity of electricity supply is a matter of profitability for industrial facilities, but it can also be a matter of safety. Loss of electricity supply can cause leakage in pipes, tanks and even process bolting in reactors. This is confirmed in numerous accident reports (such as [35]), proving that the power system must be resilient and carefully designed.

The reliable design of power systems has been extensively covered in [36] with definitions of concepts as well as golden rules for planning, operation and maintenance. The overall reliability of a power plant refers to its ability to continuously supply electricity. Power plant unavailability causing electricity outage is mainly due to (1) the unavailability of power producers, (2) their disconnection due to electrical instability or (3) the loss of the whole grid supply after a large instability.

To ensure a power plant's highest availability, the mean time between failures of power suppliers and the mean time to recover normal operation must be evaluated [37]. One part of the problem consists in optimizing the maintenance planning of each power device. However, unplanned events, measured by the failure rate of equipment (probability of unexpected loss), need to be minimized. In conventional fossil-based systems, the major risk is fossil generator breakdown, but the integration of PV systems introduces new parameters into the reliability assessment:

- $\quad$ Risk of equipment failure in the PV power plant (PV strings, inverters)

- Loss of transmission system (lines and converters) between the main bus and the PV plant.

Additionally, PV power fluctuations due to cloud passage can cause considerable power quality fluctuation that has the same impact as loss of equipment. This is a new aspect in the reliability assessment as it is not related to the reliability of the equipment, but to the site's weather conditions. This will therefore be addressed in detail in this paper.

When such events occur, load shedding can be triggered to maintain frequency and voltage (see part 3.1.1), which impacts the profitability of the system since some equipment is not fed. However, if the system becomes unstable, generators and load may disconnect in cascade to protect themselves from overspeed, leading to a complete blackout of the system [38] and therefore potentially an industrial accident. Figure 1 illustrates the reliability aspects of industrial microgrids.

${ }^{\dagger}$ Combined Cycle Gas Turbine 


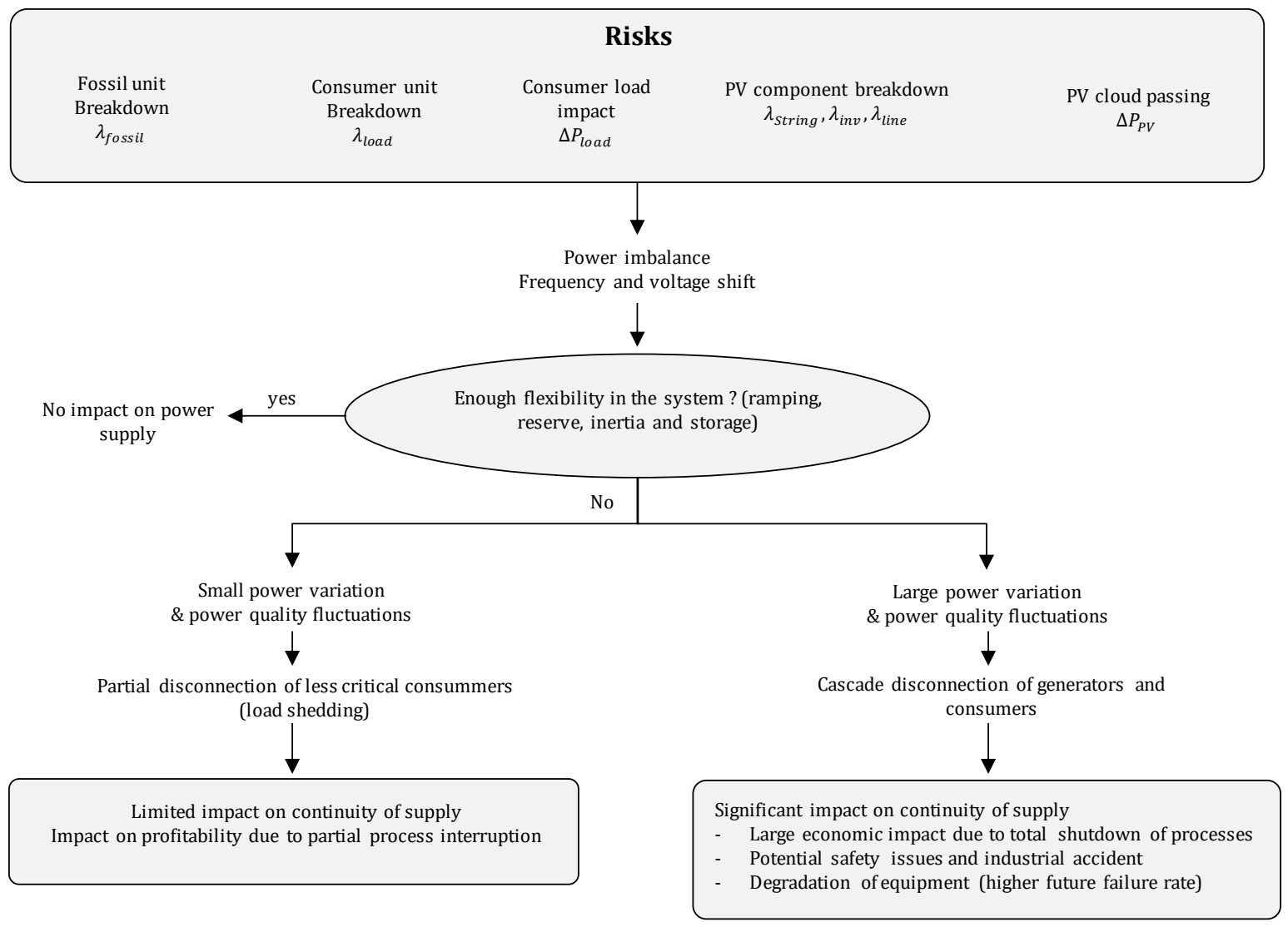

Figure 1 Summary of reliability aspects of industrial microgrids from risks to consequences. $\lambda$ refers to the failure rate (see [36]) and $\triangle P$ refers to the probability of power variation in the equipment.

If the facility is connected to a stable grid, switching from off-grid to on-grid configuration may be sufficient. However, both in weak-grid (subject to outages) and off-grid configurations, the continuity of supply relies only on the self-producing capacity of the plant [39], [40]. This motivates integrating redundancy constraints in fossil generation planning [41] and installing storage capacity to boost the flexibility of the plant. The reliability challenges of integrating more and more renewable resources into large-scale systems have been covered by island microgrid studies [42] such as those performed for the islands of La Réunion [43] and El Hierro [44]. In [45], [46] it is shown that a stochastic variation of renewable resources and a reduction of the mechanical inertia reduce the system's resiliency to power fluctuations. However, the literature only scantly covers this aspect of industrial microgrids, despite the fact that it remains critical for their long-term development [47, p. 58], [48]. When planning and operating their systems, developers must now evaluate the maximum allowable PV penetration that will still satisfy the reliability target.

\subsubsection{Focus on oil and gas applications}

Oil and gas applications $(O \& G)$ offer a wide variety of examples for industrial microgrids, since $O \& G$ has used on-site isolated electrical generation for decades. Many operating facilities, studies and future projects can provide useful feedback on experience, operational data, and even methodological insights. Some key characteristics and challenges are shared with numerous other applications, such as hospitals, military facilities, high-tech manufacturing (manufacture of electronic chips), and highly sensitive urban areas.

Due to the level of reliability required and the isolated location of $O \& G$ facilities, fossil generation is generally the only solution to produce electricity, and this participates in "well-to-wheels" emissions [49]. The increasing 
pressure of global warming has led the $O \& G$ industry to study renewable integration in its power generation units [50].

Table 2 gives an overview of studies addressing the problem of hybrid fossil-renewable power for O\&G. Wind integration and offshore platforms are the most widely covered subjects, while fewer studies have addressed the problem of onshore facilities and solar PV systems from a technical point of view. The studies highlight that electrical instabilities due to renewable resources constitute the main technical limiting factor and that storage is generally necessary to allow large-scale integration. Design optimization, such as carried out by [30], shows the interest of renewable integration for fuel and $\mathrm{CO}_{2}$ reductions. However, no parametric study including storage has been proposed to date and it is expected that the additional capital expenditure would reduce the financial benefits. Furthermore, [51] concludes that renewables will impact the fatigue and lifetime of fossil generation, which could be a major issue when reliability is a key factor.

Table 2 Review of recent studies addressing $O \& G$ microgrids

\begin{tabular}{|c|c|c|c|c|c|}
\hline Reference & [52], [53] & [30] & [54] & [51], [55] & {$[56],[57],[58]$} \\
\hline Scope & $\begin{array}{l}\text { Upstream \& } \\
\text { downstream }\end{array}$ & Offshore oil & Offshore oil & Offshore oil & Offshore oil \\
\hline Energy & Electricity, Heat & Electricity & Electricity & Electricity & Electricity \\
\hline $\begin{array}{l}\text { Power } \\
\text { range }\end{array}$ & & $40 \mathrm{MW}$ & $40 \mathrm{MW}$ & MW & \\
\hline $\begin{array}{l}\text { On grid/ off } \\
\text { grid }\end{array}$ & & Off-grid & Off-grid & Both & Off-grid \\
\hline $\begin{array}{l}\text { Renewable } \\
\text { resource }\end{array}$ & Solar & Wind & Wind & Wind & Wind \\
\hline $\begin{array}{l}\text { Fossil } \\
\text { generation }\end{array}$ & - & CCGT & CCGT & Gas turbine & Gas turbine \\
\hline Storage & & - & - & Battery & Battery \\
\hline Focus area & $\begin{array}{l}\text { Large-scale potential } \\
\text { for solar }\end{array}$ & $\begin{array}{l}\text { Method for } \\
\text { optimizing } \\
\text { design }\end{array}$ & $\begin{array}{l}\text { Power quality } \\
\text { challenges. } \\
\text { Example with } \\
\text { Hywind } \\
\text { project }\end{array}$ & $\begin{array}{l}\text { Operational } \\
\& \text { energy } \\
\text { optimization }\end{array}$ & $\begin{array}{c}\text { Electrical } \\
\text { stability study }\end{array}$ \\
\hline
\end{tabular}

Based on this brief literature review, the following specificities of O\&G facilities can be identified:

- Isolated location: O\&G rigs are often located in isolated areas or in developing countries with an unreliable grid. Facilities can be located either onshore or offshore.

- High power demand: The power delivered is rarely below $10 \mathrm{MW}$ and can exceed hundreds of MW.

- Low fuel price: As the fuel is available on-site and sometimes not valued for business, its financial value is very low (until recently, $\mathrm{CO} 2$ emissions usually incurred no cost).

- $\quad$ Proportion of torque, electricity and thermal demand: except for refineries, which consume more heat than electricity, $O \& G$ facilities almost exclusively use torque and electricity.

- Reliability and quality specifications: Strict limitations are established for frequency and voltage fluctuations as well as equipment availability. 
- Low load flexibility: For safety and economic reasons, demand must be met at all times and no shift in load can occur during the day due to unavailability of renewable resources.

- Fossil generation to ensure continuous power: The architecture features gas turbines or internal combustion engines with redundancy constraints to prevent generator loss from causing a system failure.

This overview shows the interest of $O \& G$ microgrids to identify the challenges and to highlight success stories of other industrial applications in isolated areas. In a research perspective, $O \& G$ microgrids provide interesting case studies and make it possible to compare results and validate them in a similar environment before considering their adaptation to other applications.

\subsection{Research challenges and paper summary}

From the review presented above, the following research challenges are identified:

- Due to their relatively small size compared to large grids, industrial power systems are more vulnerable to electrical instabilities[54]. However, industrial facilities cannot afford unplanned blackouts and electricity shortages. This calls for the development of a method to ensure an equilibrium of active and reactive power with a high degree of reliability.

- Reliability constraints make it necessary to consider unplanned power fluctuations brought about by the integration of PV systems. Equipment breakdowns can easily be integrated in the reliability assessment process by following the same procedure as fossil generation breakdown. However, the impact of short-term stochastic solar variation on continuity of supply is much more challenging to evaluate.

- At short time-scales, the variability of PV power remains subject to significant uncertainties, and is the main reason for power imbalances in the grid. Methods for quantifying and forecasting short-term ramps are still under development, as well as models that account for the effect of a plant's geographic dispersion. As the impact of solar variability increases with the penetration rate, accurate models are an absolute necessity to reliably plan industrial microgrids.

- Flexibility levers used to compensate renewable power variations are crucial to ensure grid reliability. Storage systems are the subject of increasing investigation, while less attention is being paid to fossilfuel technologies due to their apparent maturity. But their response to successive ramps remains unknown and may significantly alter their lifetime and fuel consumption. Very few models account for their dynamical behavior or integrate it in a long-term assessment.

- A large number of studies now address the control and management of microgrids to smartly interconnect all power devices on the grid. This involves making the right trade-off between economic performance and robustness. Reviews of existing technologies should take this point of view in order to identify the appropriate strategies to implement.

This paper intends to contribute to filling these gaps as follows. First, we present research questions related to the integration of renewables into reliability-constrained industrial microgrids. For the sake of succinctness, only solar-PV applications are covered in this paper. We then provide a review of the short-term dynamical assessment of PV systems and fossil generation. Next follows an investigation of real-time control strategies that ensure reliability and power quality within industrial microgrids. Fourthly, we propose a discussion of the main findings and compare them with previous literature review studies. The final section concludes and suggests future avenues for research. 


\section{Review on power supply technologies}

\subsection{The challenge of solar-power variability}

Integrating PV systems in industrial power plants brings additional risks for the continuity of supply and may therefore reduce the reliability of the power plant. Reference [59] provides an overview of reliability assessment methods for PV inverters, modules, transmission systems, and overall distribution systems based on fault analysis. Insights on the impact of aging and weather conditions on reliability over the lifetime of a plant are provided in [60], showing that high average ambient temperature is likely to increase failure rates (almost 10\% after 5 years in the case of a PV system in Arizona against 0\% in Denmark). This factor must therefore be considered in reliability analyses. In [59], solar variability is mentioned as one of the main future challenges for distribution systems; however no insights are given on its impact on reliability. This is why a special focus on solar variability assessment is provided in this study.

Solar photovoltaic (PV) power is traditionally assessed with a quasi-static framework, as only hourly variations are of interest for economic evaluation [15]. As previously mentioned, the vulnerability of large-scale isolated power systems motivates a study of sub-hourly phenomena that might impact electrical stability. Hence, shortterm variability is a key element to ensure the balance between production and consumption and therefore a high level of reliability. Eq. 1 shows the relationship between the power produced by a PV panel and the solar irradiance[61].

$$
P_{P V}=P_{\text {installed }} * \frac{G H I_{\text {plane of array }}}{1000} *\left[1-K_{\theta}(\theta-25)\right]
$$

where $K_{\theta}$ is the temperature sensitivity coefficient, $P_{\text {installed }}$ the rated capacity of the panel in ISO conditions, and $G H I_{\text {plane of array }}$ the Global Horizontal Irradiance calculated in the plane of the panel. The actual amount of energy collected by the panel will depend on additional factors [62] such as the clearness of the sky, the performance of the PV panel (efficiency, temperature sensitivity, aging etc.), shade and fouling due to the surrounding environment, etc. However, only GHI variation significantly impacts the system at short time-scales.

Cloud passage is the main contributor to short-term variability and needs to be addressed carefully. Figure 2 shows an example of solar irradiance variability over two days with a 1-second time-step.
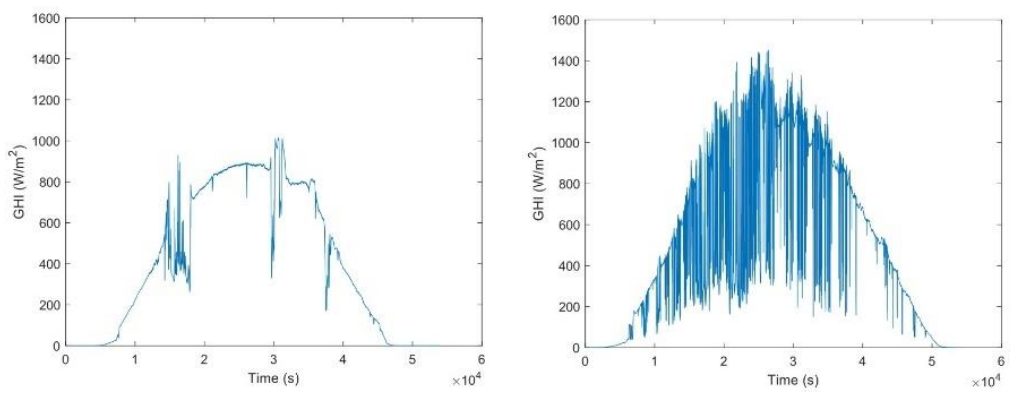

Figure 2 Two irradiance profiles captured with 1-second sampling [63].

The following sub-sections will focus on the approaches implemented to explain, measure and forecast shortterm solar variability in order to integrate the risk of power imbalance in an industrial microgrid. 


\subsubsection{Different approaches to address PV variability}

Solar variability affects the irradiance measured by sensors as well as the power produced by one or several PV panels. Two time-scales are important for microgrid operation and planning:

- Solar power range: difference between the minimum and maximum solar power output within a time interval (typically 15 minutes to 1 hour).

- Solar ramps: the change in solar power or irradiance in a short time interval (within the range of the sampling interval: 1 second to $1 \mathrm{~min}$ ) that dispatchable units will have to instantly compensate.

Solar range and solar ramps are necessary to calculate the amount of spinning reserve, the ramping capacity of dispatchable units, and the storage capacity requirements. In high-reliability applications like industrial systems, extreme ramp events are also of interest to make a robust assessment.

\section{A variability indicator to accurately account for perturbations}

It is possible to assess the level of variability over an entire day in order to determine the frequency and magnitude of perturbations. The variability index as defined in [64] is the ratio between the length of global irradiance series and the length of clear sky irradiance over a defined time interval (the study proposes to calculate the variability index over 1 day). In [65], 6 metrics are compared to evaluate the solar variability on 31 test days. The study proposes a new indicator based on integrating the cumulative density function of solar increment. According to the study, these metrics can be used to characterize the variability at both high and low frequencies and classify days depending on the perturbations.

\section{Climate-dependent variability}

Location plays a role in solar variability due to climate type, orography and vegetation (large forests also generate clouds during daylight). A solar variability map of the US drawn up using high-resolution production data [66] shows significant differences between desertic-arid areas and islands like the Lau islands and Hawaii where the highest level of variability is observed. In [67], the author studied the relationship between the clearness index and solar variability for locations in different climate zones. The authors concluded that climate zone and weather-driven clouds may have less impact on variability that the orography of a site. It is expected that the small, fast-moving clouds formed by the relief may have a bigger impact on short-term variability.

\section{Impact on PV systems}

A PV system's short-term variability is different from the irradiance variability observed from a single sensor. In [68] it is concluded that the power profile entirely follows the irradiance profile for time ranges greater than 10 minutes. However, short-term variability is affected by the size, shape and distribution of a plant. For plants of several megawatts, 1 -s, 10-s, and 1-min ramps can be approximately $60 \%$, 40\%, and 10\% smaller, respectively, than those measured by a pyranometer. These results are confirmed in [69] and [70].

\subsubsection{Modeling solar system variability}

\section{Smoothing irradiance data to obtain PV Power}

Since PV power transients are smoother than irradiance transients, considerable work has been done to obtain a realistic power output from the data employing a single irradiance sensor. A dispersion factor is used in [71] to characterize different types of layout (crowded or spacious), and the irradiance variability is smoothed to obtain the power production in several configurations. In [72], this concept is used to calculate the extreme ramp rate of a power plant. In [70], the authors proposed a transfer function with empirical coefficients to address variability smoothing and compare the results with six multi-megawatt power plants. 
A Wavelet Variability Model (WVM) is proposed in [73] to obtain a PV power time-series from irradiance data. The WVM is compared to three other methods: linear scaling, moving average, and averaging on every sensor available. When compared to the 2MW output power, the WVM outperformed the three methods, especially when evaluating the maximum ramp rates.

\section{Modeling solar variability by generating stochastic time series}

Assessing solar variability is a big challenge if no high-resolution irradiance data are available on-site. One solution is to generate an irradiance profile based on numerical weather prediction or satellite predictions. In [75], methodologies based on Markov chains are proposed to generate irradiance and a clear-sky index profile. [76] reproduces high-frequency patterns of historical data to increase the temporal resolution of satellite prediction. However, these methodologies require a representative training dataset of high-resolution ground measurements, which requires to have closely located sensors available. Recently, [77] paved the way for generating $1 \mathrm{~min}$ data without ground measurements, but concluded that additional research needs to be carried out in order to obtain finer resolution.

\subsubsection{Forecasting of solar irradiance and variability}

Solar forecasting has been a growing topic in recent years since it provides valuable information for microgrid operations and is used for various purposes, such as market trading, reserve scheduling, genset planning, and storage management [78]. Its potential to optimize battery sizing and lower the LCOE of ramp-constrained multimegawatt power plants is highlighted in [79]. Capturing solar variability with forecasts may consist in providing either very short-term production estimations or an indicator of the variability to be expected for a large horizon (15 $\mathrm{mn}$ to $1 \mathrm{~h}$ ) [80], [81]. As an example, [82] proposes a methodology to estimate the largest ramp rate by analyzing cloud shadow velocity and irradiance sensor measurements.

Satellite irradiance forecasts and numerical weather predictors are now widely used and can be accessed online [83]. Due to their large time and space resolutions, a downscaling approach is necessary to predict the variability at 10-second or 1-minute scales. Such solutions are proposed in [84]-[86], but due to the geographical dependency of the variability, no generic method has been proposed to downscale satellite prediction without high-resolution data at the specific location.

Sky imagers have been developed and commercialized in recent years with the intention of providing very short-term predictions for spinning reserve management (diesel load margin, storage capacity, etc.) [87], [88]. The development of these techniques will be a key factor of success for the reliable management of industrial microgrids.

Finally, in-situ measurements can enable forecast processing with a very high resolution [89][90]. One criticism of this technique is that the sensor network has to map a large area or be carefully placed depending on the general cloud cover. If not, clouds may be inaccurately described and, consequently, solar variability and ramp events will be misevaluated.

\subsection{Fossil generation}

With the penetration of variable and uncertain renewable power, fossil generation (mainly gas turbines and internal combustion engines) is about to dramatically change from a steady-state operational paradigm with a fixed load and a well-known production plan to a constantly changing demand subject to stochastic perturbation. This obliges manufacturers and users to ensure operational flexibility [91] with an increasing number of start-ups, shut-downs and fast load changes, and increases the need for power-quality control. Meanwhile, cost-effectiveness, reliability and emission regulations compliance need to be guaranteed. 
As an example, Northern Ireland has identified the need for flexibility as a major issue for a large-scale renewable integration [92]. The potential wind curtailment was assessed using hourly wind ramp analysis. The study shows the great potential of thermal generation flexibility for guaranteeing energy balances.

The main objectives for thermal generation in industrial applications can be summed up as follows:

1. Adapt the power output to match the power needs.

2. Provide enough primary response to ensure frequency and voltage stability.

3. Maintain the highest level of availability when operated in extended transient mode.

4. Ensure cost-efficiency in the long run with regards to O\&M costs and aging.

5. Guarantee compliance with emission regulations in transient operations.

As performed in [93], numerous commercial studies attempt to compare fossil generation flexibility for hybrid generation purposes. To ensure that such comparisons are creditable and accurate, performance assessment needs shift from steady-state, off-design correlations to dynamic modeling at a short time-scale.

For project developers, making a choice based on a generator's dynamical performance is not an easy task:

- Ramp-up capacities are rarely provided by manufacturers for small time-scales (seconds).

- Manufacturers usually provide ramp-up capacities for fast start-ups and shut-downs, which are meant to be occasional.

- There is no guarantee that the thermodynamic parameters (pressure, temperature, etc.) will remain within acceptable limits.

- No insights are provided on the machine's performance: fuel consumption, emission, fatigue.

These reasons call for a deeper understanding of fossil generator dynamics and more detailed modeling. The next part presents some theoretical aspects as well as the state-of-the-art on dynamic modeling of fossil assets.

\subsubsection{Gas turbine}

\subsubsection{Working principles}

Gas turbine (GT) theory has been widely developed in past decades and detailed in a large number of references [94]-[96]. GT performance predictions have been one of the main concerns in order to evaluate differences between ISO parameters provided by manufacturers and user's operating conditions. Figure 3 and Figure 4 show the main components of single-shaft and twin-shaft gas turbines.

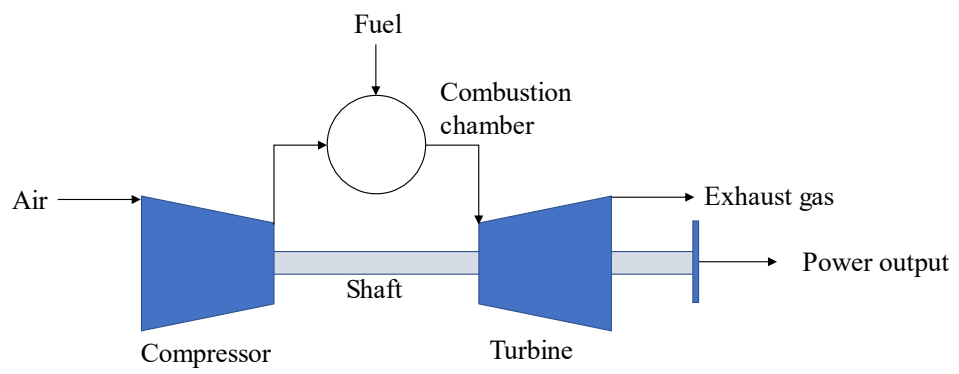

Figure 3 Single-shaft gas turbine [94]. 


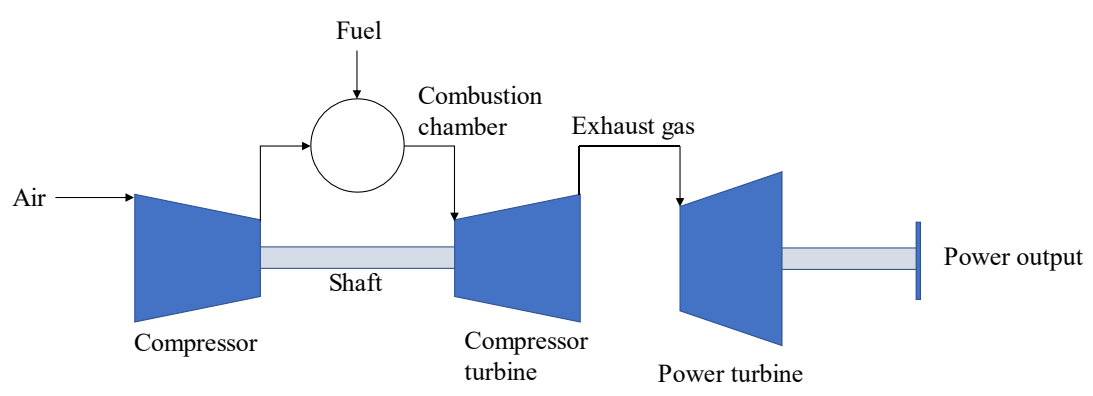

Figure 4 Twin-shaft turbine [94]

As shown in Figure 5, the compressor crosses iso-efficiency lines during transient operation and therefore increases the turbine's fuel consumption and particle emissions and impacts its mechanical fatigue [95, p. 268]. Acceleration and deceleration are also constrained by surge and flameout limits that need to be taken into account to assess the ramping capacity of the turbine.

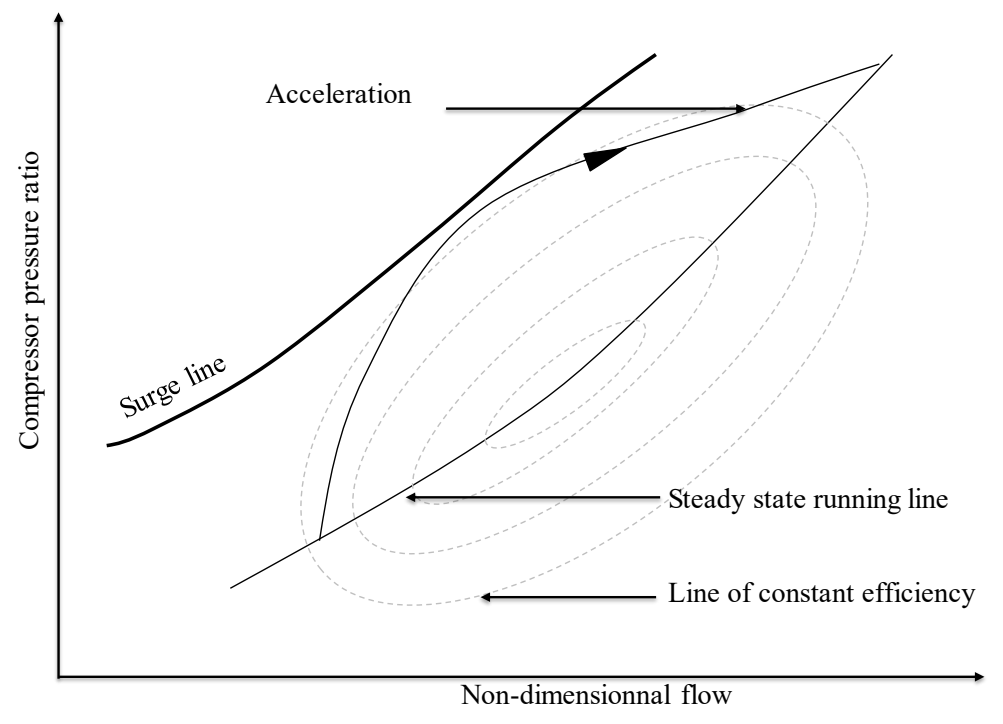

Figure 5 Compressor transient running line.

\subsubsection{Representation of dynamical behavior}

The thermodynamic relationships of the components can be used to simulate the steady-state "off-design" points due to part-load operations, special weather conditions, etc. This methodology can be found in the literature and is used by commercial software like ThermoFlow [97] and Proosis [98] but only represents static conditions.

The development of dynamic models for the performance prediction of gas turbines is still the subject of considerable research. Various methodologies with a growing degree of complexity can be used [99]. Computational-Fluid-Dynamics (CFD) models are probably the most accurate, but the level of complexity may go beyond the needs of renewable integration studies. Moreover, these models require large computing capacities and perfect knowledge of the components' geometry.

Some studies propose "black-box" models based on artificial intelligence in order to learn and reproduce the behavior of an asset based on operational data [100]. Zero-D (0-D) modeling appears to be a good trade-off between a comprehensive approach and complex calculations. Several levels of complexity exist here as 
detailed in reference [101], which compares different modeling techniques for power quality studies. The paper shows that significant differences are obtained if physical parameters are ignored, such as ambient temperature.

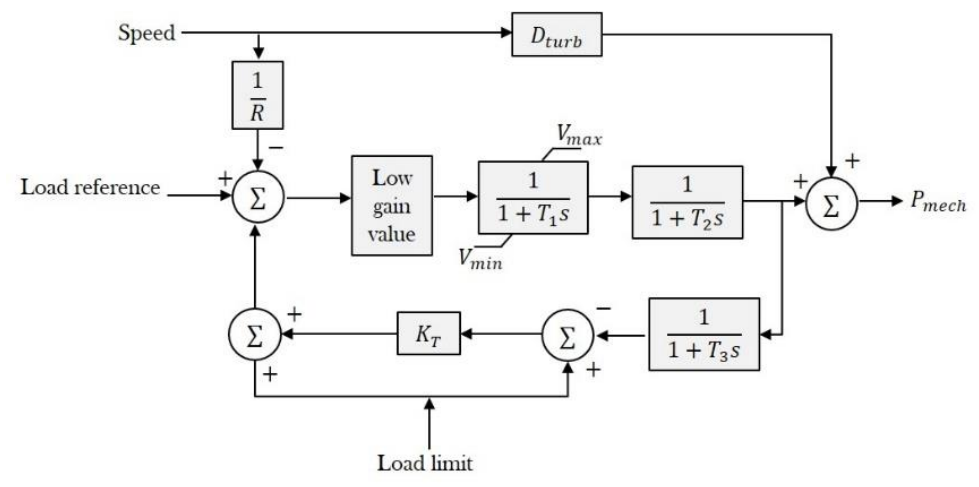

Figure 6 The GAST model as presented in [101]. The capacity of the generator to provide power as a function demand is modeled using time constants Ti and saturations $V$.

A similar 0-D representation is introduced in [102] [103] and [104] (which also introduces the intercomponent volumes method). Blocks are obtained by implementing a Laplace transformation of thermodynamic equations.

Reference [102] proposes a MATLAB/Simulink model of a dual-shaft turbine. This reference provides a control scheme for Gas Turbines (GT) for the purpose of a wind-GT hybrid power plant and simulates 10 hours of operation. The same modeling technique is applied in [105] to perform a gas turbine diagnostic under transient operation. Reference [103] proposes a dynamic modeling of a single-shaft turbine featuring VIGV (Variable Inlet Guide Vanes). The simulation time is typically 10 minutes.

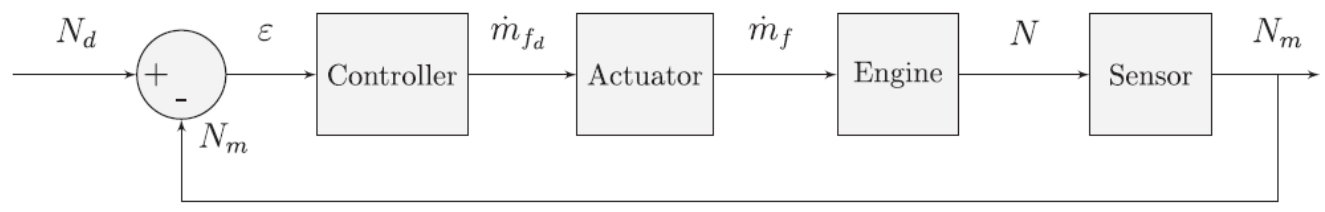

Figure 7 Dynamic model of the engine and its regulation system [102]

In references [102], [103], a model is calibrated with steady-state data using an advanced iterative technique to minimize the error between the model's results and a benchmark provided by verified data (e.g. PROOSIS or ThermoFlow software). These methodologies may provide tools to represent the behavior of gas turbines. The parameters vary from one turbine to another. For a 0-D representation, a compressor map and a turbine map are necessary. This information has to be made available by manufacturers, which creates a strong barrier to study and compare their performances.

Two references point to an interesting compromise between data requirements and accuracy, with a "component-based" approach using the Modelica environment [106], [107]. The models should be easy to adapt from one gas turbine to another, and results show good accuracy compared to experimental data.

To date, gas turbines have rarely been used for renewable microgrids despite their significant potential [108]. Based on their model, [102] show that hybrid gas/wind power plants can reduce both fuel consumption and $\mathrm{NO}_{x}$ emissions by at least $40 \%$. However, $\mathrm{NO}_{x}$ reduction is debatable, as pointed out in [109], where an increase in $\mathrm{NO}_{\mathrm{x}}$ emissions from large-scale, gas-fired power plants has been observed for shares of renewables below $30 \%$. Due to increasing pressure from emissions regulations, the question of emissions modeling for 
transient operations and the integration of selective catalytic reduction will undoubtably be a key challenge for researchers in the future.

\subsubsection{Internal combustion engines}

\subsubsection{Working principle}

Research on diesel engine modeling has mainly focused on propulsion applications [110] and only a few references study its behavior in power systems [111], [112]. The principle of a diesel generator is basically the same as an automotive diesel engine: combustion within the pistons drives the crank shaft, which provides mechanical torque to the electric generator. This process follows the Carnot thermodynamic cycle.

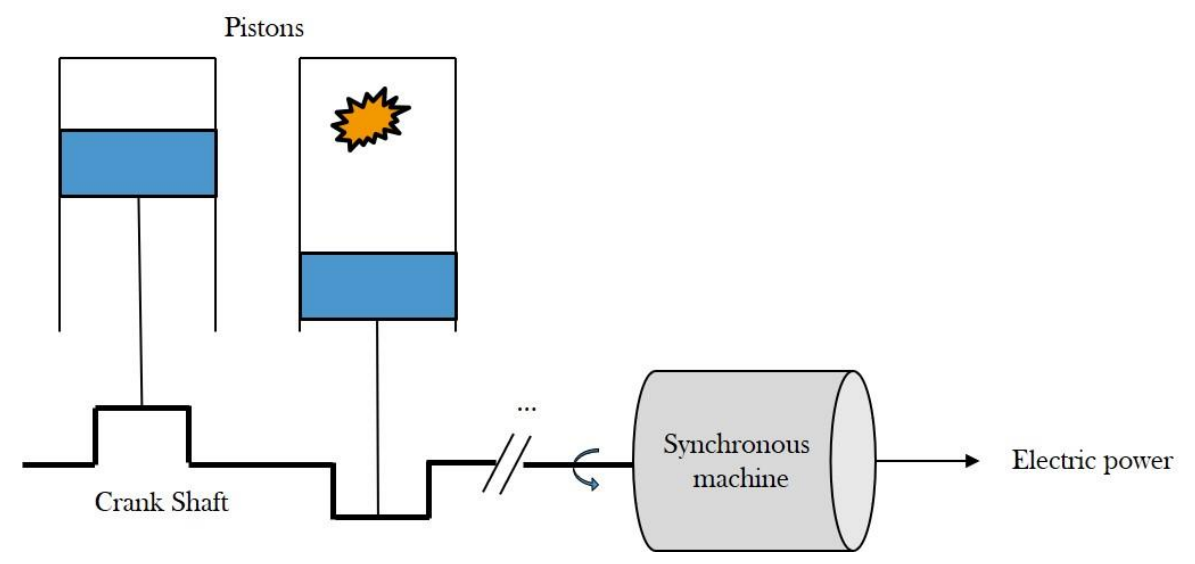

Figure 8 Principle of ICE power conversion from combustion to electricity supply.

\subsubsection{Representation of dynamical behavior}

Unlike for gas turbines, manufacturers tend to provide more insights on the short-term dynamical behavior of their engines since this is a key selling argument. Nevertheless, the impact of a repeated load increase remains unknown and a detailed thermodynamic modeling is necessary.

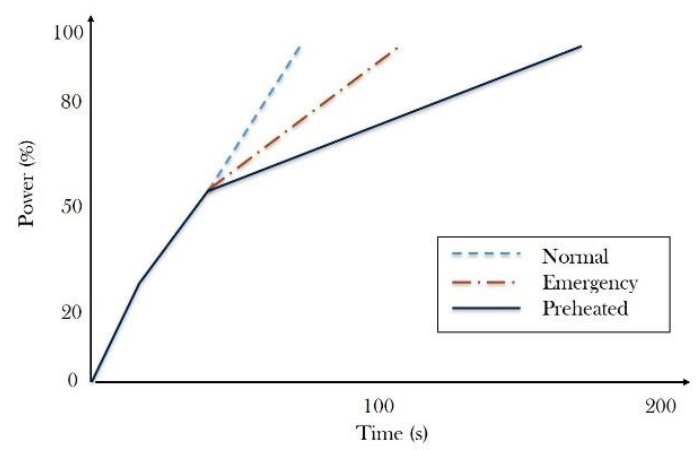

Figure 9 Recommended load increase of Wartsila W32 according to the product guide [113]

\section{Thermodynamic approach}

The thermodynamics of the transient operation of ICE are widely covered in references [114] and [115]. Two main modeling approaches can be used considering either a continuous phenomenon (mean-value model) or discrete events for combustions within the pistons (discrete-event models). 
Both methods aim at describing the change in the pistons' input parameters (air mass, fuel mass and exhaust gas recirculation) when a torque command is given to the system as described in Figure 10.

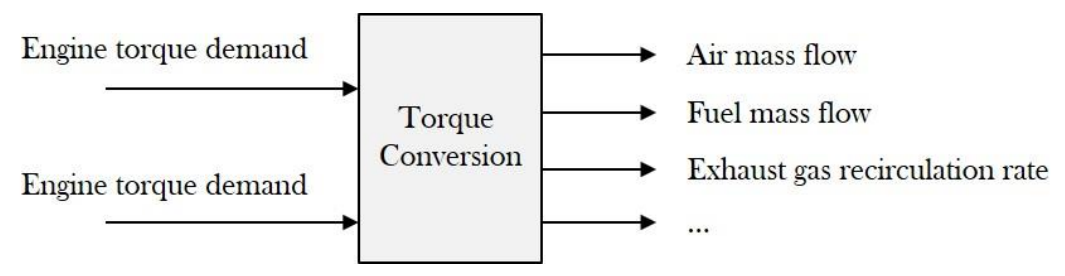

Figure 10 Principle of torque regulation

In [112, p. 748], several modeling approaches are described, many of which are based on highly complex fluid mechanics. However, a lack of data on the engine's geometry makes it impossible to implement such a model. Moreover, this study intends to be adaptable to multiple types of engine.

Reference [116] presents a simple mathematical model of an engine based on thermodynamic expressions, enabling a fairly accurate study of the engine's step load response. The parameters needed for the simulation are generally not available in the literature and the author recommends calibrating the model using experimental data.

Finally, reference [117] provides a simple methodology to model the transient behavior of a diesel engine. The model is calibrated with experimental data and requires accurate turbocharger parameters to run.

\section{Reduction to a time constant}

From a control-science perspective, the transient modeling of a diesel engine mainly consists in describing 4 main components: the regulator (controller), the actuator, the engine's combustion, and the synchronous generator. In ref [118], [119] dynamic models are proposed for the frequency control (taking actions on the angular velocity) and therefore represent the short-term transient response of the engine.

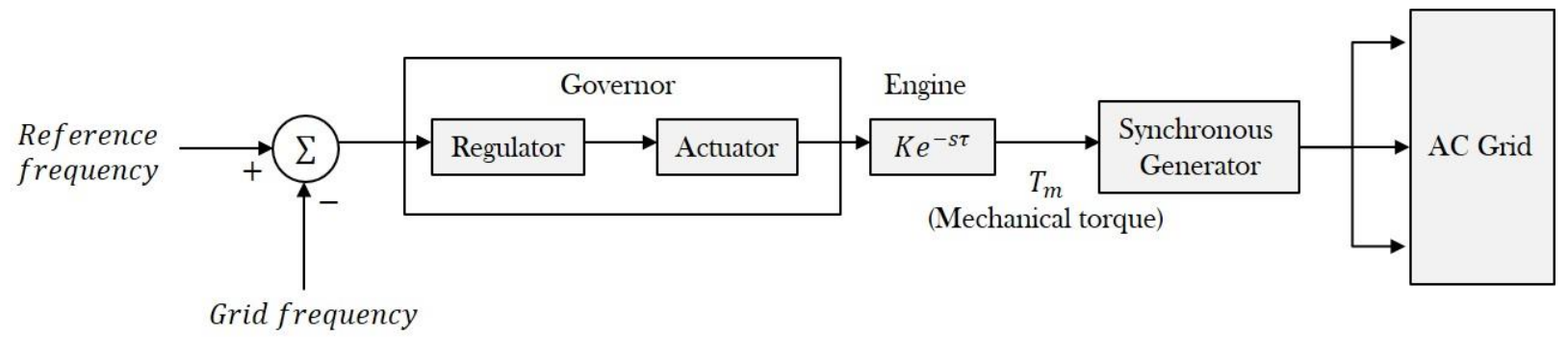

Figure 11 Conventional diesel engine representation [118].

The above-mentioned references are based on a mathematical modeling of the machine's processes and components. Other modeling techniques consist in "learning" the engine's response using neuro-computing. In ref [120], an HIL test bench is combined with a real diesel engine in order to learn the frequency's transient behavior and control. A dynamic model is then built to conduct stability analysis. However, this approach gives a very poor understanding of the machines, which makes it very difficult to adapt to other engines with, for example, a different number of pistons.

Studies [121], [122] implement a promising methodology using GT-SUITE software with a good understanding of components and available component libraries for dynamic modeling.

The different methods implemented for assessing the engine's flexibility potential have many advantages. Firstly, they extend comprehension of the engine and may allow more accurate stability studies. For example 
in [123], a sensitivity analysis of the engine injection delay is carried out. The results show that a short time delay significantly improves the grid's frequency stabilization. The study recommends a low injection time delay (mostly found in high rotational speed engines) in order to improve the penetration rate of renewables.

A good comprehension of the thermodynamical limitation is also a very important factor in renewable integration. In [124]-[126], it is shown that a high penetration rate can be enhanced by low-loading engines featuring dedicated pre-heating and clutching systems.

\subsubsection{Aging and maintenance considerations related to PV variability smoothing}

Is has been observed that fossil generators will increasingly be operated in a transient state with rapid variation to smooth out solar variability. The evolution of fatigue and fault probability due to transient operation is still poorly addressed by the scientific community. [127] evaluates the impact of an extended dynamic operation of CCGT, and indicates that the lifetime reduction may be up to $10 \%$ greater than in reference steady-state cases. Further analysis would be necessary to evaluate the failure rates of typical fossil technologies in industrial microgrids. Solar variability modeling may once again prove crucial for such an evaluation.

\subsection{Storage systems}

Storage systems may achieve two different objectives in microgrids: energy shifting and system services. System services are applications dedicated to enhancing a system's reliability when subject to unplanned events. For example, a storage system can provide power fast if the renewable output suddenly decreases or if a fossil generator trips (Figure 13). The storage device is therefore used as a buffer to compensate for the start time and ramp of the replacing unit.

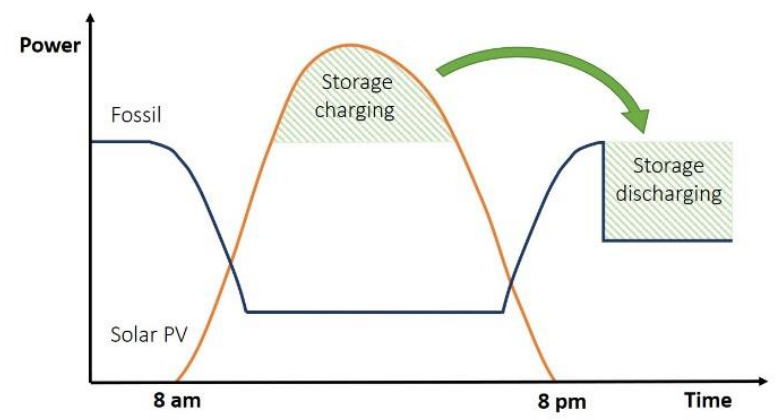

Figure 12 Peak-shaving storage system

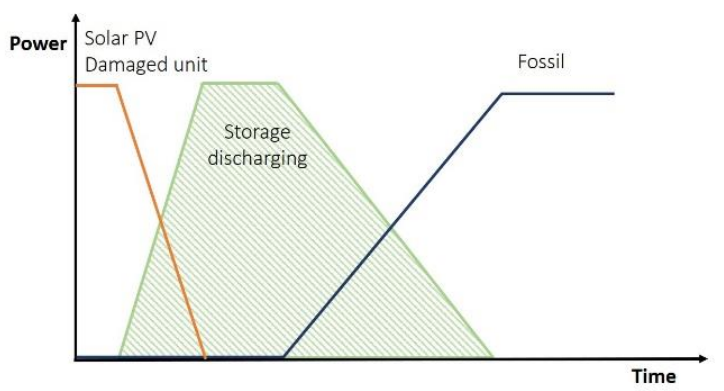

Figure 13 Buffer storage system 
Depending on its objectives, a storage system will have technical specifications that require carefully choosing the technology. [128] gives an outstanding overview of storage technologies in microgrids and provides examples for the five main types of storage technology listed in Figure 14.

Thanks to the variety of storage technologies available, numerous applications are covered, from very small uninterruptible power systems to utility scale systems such as pumped hydro. Figure 15 shows the general trends of technologies according to their rating capacities and discharge times (additional features for technology comparison can be found in [129]).

Considering the characteristics of industrial microgrids and their production units, storage systems must contain several MWs in order to provide services with reaction times varying from a few seconds to several hours. Li-Ion batteries, flywheels and supercapacitors seem to be the most suitable options for these applications [129], [130], depending on the final use of the energy (for instance, heat storage may be the best option if the final service requires heat).

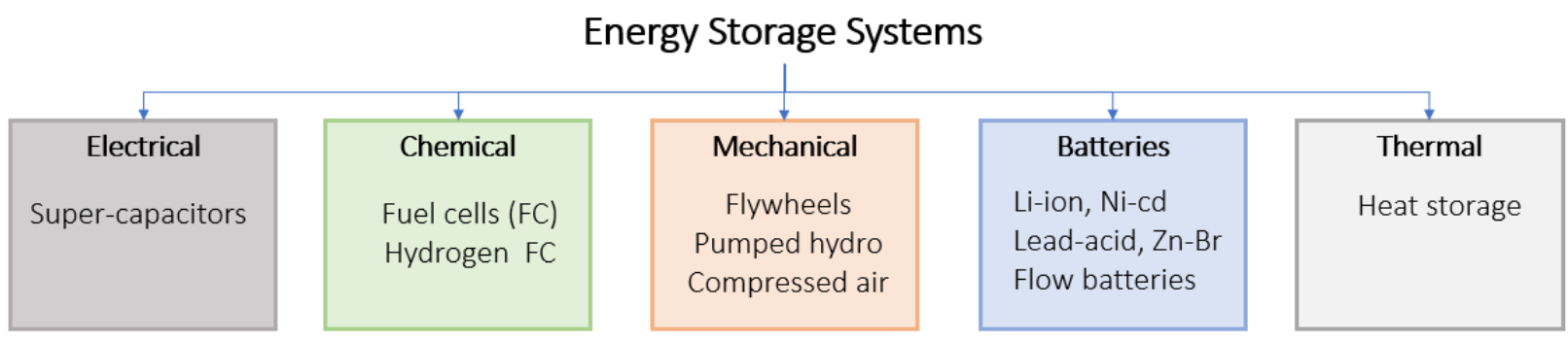

Figure 14 Categories of storage technology [129].

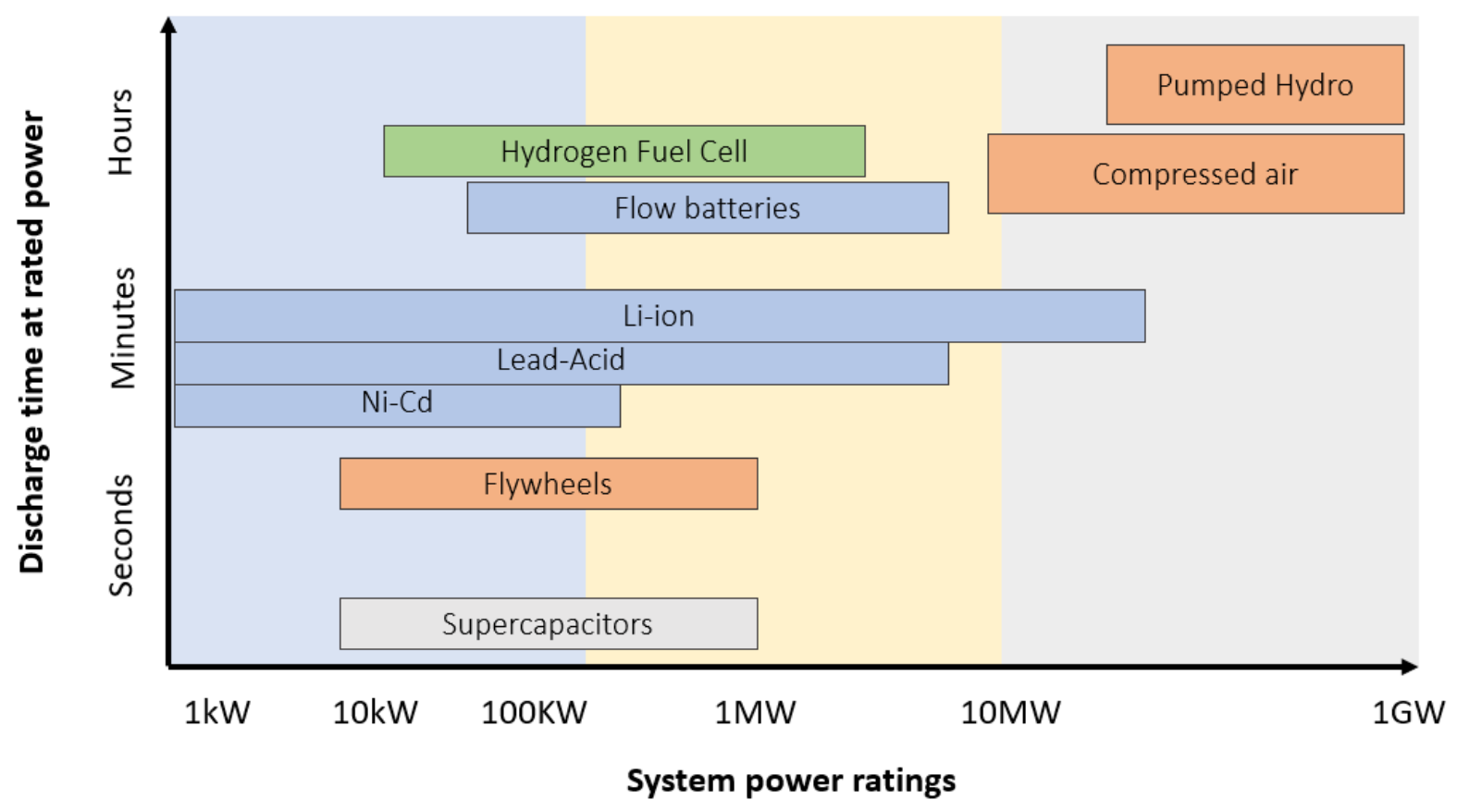

Figure 15 Discharge time and power ratings of storage technologies [128], [131] 
Table 3 Review of the most relevant technologies for reliability-constrained industrial microgrids

\begin{tabular}{|l|l|l|l|l|}
\hline Technology & References & Advantages & Drawback & Comment \\
\hline Li-ion batteries & [128], [132], [133] & $\begin{array}{l}\text { High energy } \\
\text { density, high } \\
\text { cycling efficiency, } \\
\text { rapid response } \\
\text { time, low self- } \\
\text { discharge } \\
\text { Applicable to } \\
\text { other uses (energy } \\
\text { shifting) }\end{array}$ & $\begin{array}{l}\text { Lifecycle } \\
\text { degradation due to } \\
\text { cycling and } \\
\text { thermal effects. }\end{array}$ & $\begin{array}{l}\text { Market leader. } \\
\text { Drawn by } \\
\text { synergies with } \\
\text { automotive } \\
\text { applications } \\
\text { Recent economies } \\
\text { of scale. }\end{array}$ \\
\hline Flywheels & {$[134],[135]$.} & $\begin{array}{l}\text { Quasi-infinite } \\
\text { number of cycles }\end{array}$ & $\begin{array}{l}\text { Low energy } \\
\text { density } \\
\text { High self- } \\
\text { discharging rate }\end{array}$ & $\begin{array}{l}\text { Low maturity, high } \\
\text { costs }\end{array}$ \\
\hline Supercapacitors & {$[136]-[138]$} & $\begin{array}{l}\text { High power } \\
\text { density, long } \\
\text { lifetime and } \\
\text { limited aging. } \\
\text { rate (up to 40\% a } \\
\text { day). }\end{array}$ & $\begin{array}{l}\text { Suitable only for } \\
\text { very short-term } \\
\text { applications. Low } \\
\text { maturity in large- } \\
\text { scale applications }\end{array}$ \\
\hline
\end{tabular}




\section{Operation of industrial microgrids}

Most studies of microgrids tackle the problem of operation and planning by handling a single aspect of the microgrid (control, energy management or sizing). However, due to the specific characteristics of industrial microgrids, each should be subject to careful attention. As a matter of fact, the size of a facility impacts power quality problems and endangers the continuity of operations. Secondly, operational costs are part of product profitability and must be optimized. Finally, as industrial power plants require huge investments, reliable sizing is crucial. Control, energy management, and sizing are three steps in a single process that aims at finding the best operational scenario for the microgrid. Figure 16 shows the different time-scales for the main actions and phenomena that take place during the microgrid's lifetime.

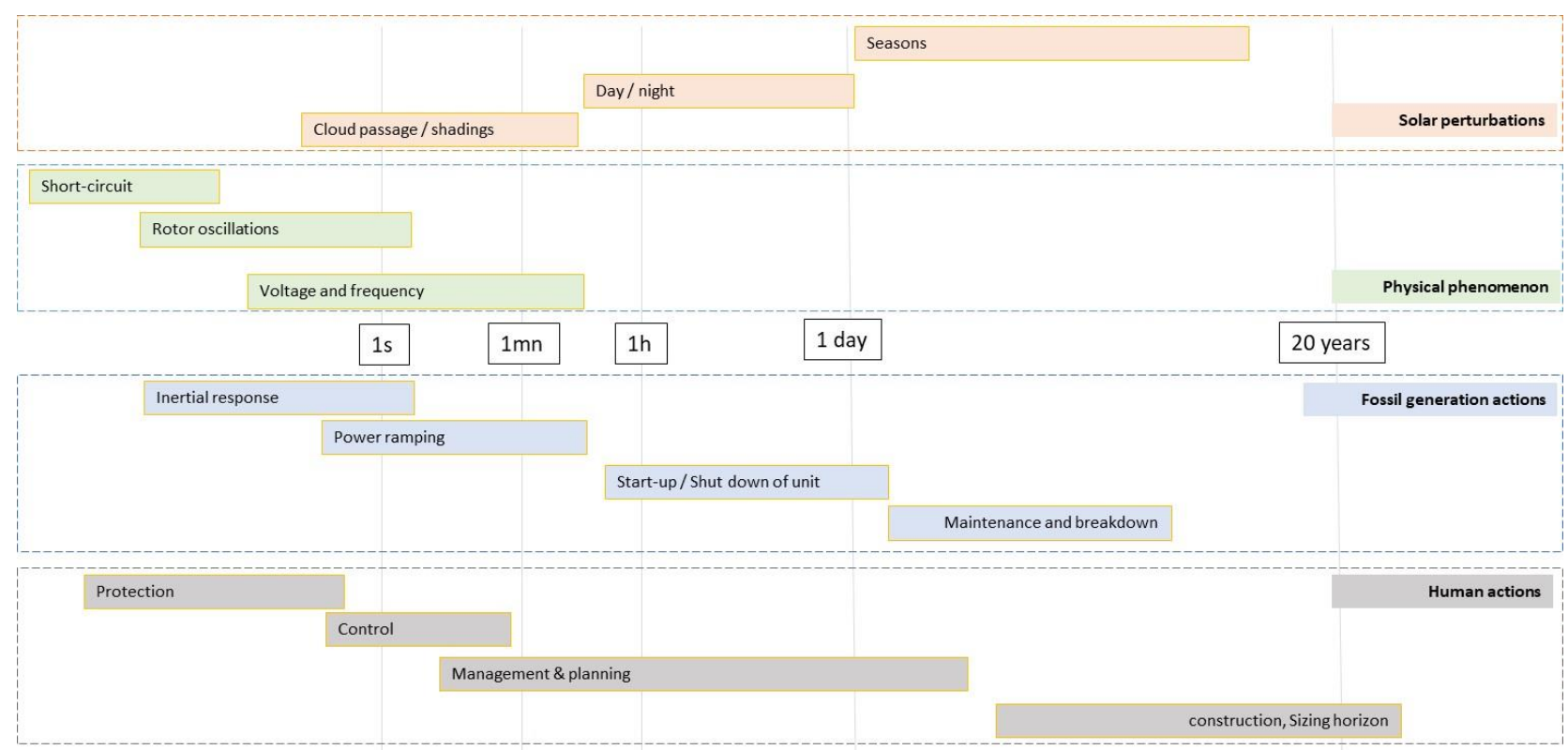

Figure 16 Different time-scales for planning and operation of power systems inspired by [139]

\subsection{Short-term power control}

The performance of a microgrid is closely related to its control scheme since it is supposed to execute the production plan, while protecting the power system and devices when instabilities occur. Microgrids ensure a reliable electricity supply by following power quality specifications and protect the devices from going out of their operational range. In industrial microgrids, special attention is paid to the frequency and voltage control.

\subsubsection{Fundamentals of frequency and voltage regulation}

In a synchronous electricity network, the value of the frequency needs to be the same at every point to avoid generator de-synchronization and allow proper use of the equipment. This means that all of the synchronous generators feeding the system must share the same rotor angle velocity $\omega$ as this is directly linked to the frequency (Eq. 2). When a global imbalance of active power occurs in the system, the swing equation (Eq. 3) expresses the fluctuation of the frequency [140].

$$
\omega=2 \pi f
$$

Eq. 2 


$$
\frac{d \Delta f}{d t}=f_{0} \frac{P_{g e n}^{p u}-P_{l o a d}^{p u}}{2 H}
$$

Similarly, local voltage fluctuation can occur due to reactive power imbalances. The network's topology plays a major role and stability assessments require more information on the system. The general sensitivity of the voltage and rotor angle $(\Delta V, \Delta \theta)$ on active and reactive power $(\Delta P, \Delta Q)$ is expressed as follows [140] ( $\mathrm{J}$ is the Jacobian matrix expressing the sensitivity of the system):

$$
\left[\begin{array}{l}
\Delta P \\
\Delta Q
\end{array}\right]=\left[\begin{array}{ll}
J_{P \theta} & J_{P V} \\
J_{Q \theta} & J_{Q V}
\end{array}\right]\left[\begin{array}{l}
\Delta \theta \\
\Delta V
\end{array}\right]
$$

Voltage stability can be handled at relatively low costs with available commercial technologies. In addition, reactive power compensation capacities (such as capacitor banks) are more affordable than active power compensation capacities (which are new production units, such as storage or fast fossil generation). This means that the techno-economic balance will be less impacted by making adjustments to reactive capacities through the successive sizing steps. Finally, unlike for active power, reactive power can be produced by all devices, which gives more flexibility to the system. This is why assessing the impact of variable energy resource penetration on voltage stability can be considered less important than assessing frequency stability problems [141], [142].

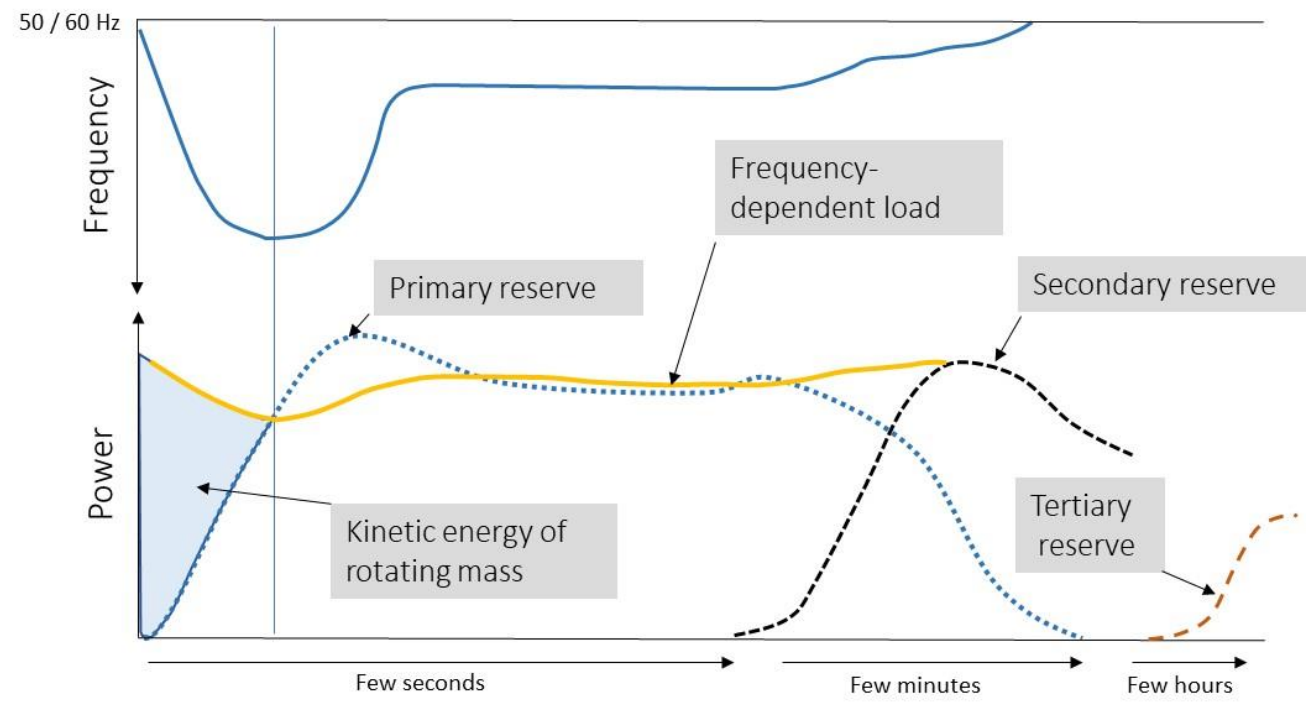

Figure 17 Evolution of frequency after a sudden load step [143].

\section{The role of inertia in passive regulation}

As seen in Figure 17, the kinetic energy delivered in the first few seconds is much greater than the primary reserve and frequency-dependent load reduction. When a sudden power imbalance occurs, mechanical torque takes place as both sides of the alternator shafts cause a deceleration. The inertia softens the shaft's deceleration by returning the kinetic energy stored in the rotating mass [140]. The inertia constant $H$ (sec) accounts for the kinetic energy stored in the synchronous machine. It is calculated as a function of the angle velocity $\omega(\mathrm{rad} / \mathrm{sec})$, moment of inertia $J\left(\mathrm{~kg} / \mathrm{m}^{2}\right)$ and power rating of the unit (MVA). 


$$
H=\frac{1}{2} * \frac{J \omega^{2} * 10^{-6}}{M V A_{\text {pu rating }}}
$$

The inertia constant of a system is the sum of the individual inertia constant $\mathrm{H}$ of each generating unit $i$ $\left(H_{\text {total }}=\sum_{i} H_{i}\right)$. Due to the increasing penetration rate of renewables, industrial microgrids tend to have less inertia in their systems. This is due to the fact that the inertia values of diesel generators and gas turbines are lower than those of large conventional fossil units (see Table 4), and because units may be shut down when renewable power feeds the system.

Table 4 Value of inertia constant for several production units[143].

\begin{tabular}{lc}
\hline Type of production unit & $\begin{array}{c}\text { Inertia constant } \\
(\mathbf{s})\end{array}$ \\
\hline 600 MW steam turbine & 13.7 \\
\hline $11 \mathrm{MW}$ average speed diesel engine & 3 \\
\hline 21 MW average speed diesel engine & 5.2 \\
\hline 30 MW gas turbine & 2.5 \\
\hline Photovoltaic generator & 0 \\
\hline
\end{tabular}

In a microgrid, maintaining enough inertia is crucial to ensure the grid's stability. This aspect must be considered with the same care as active control actions. This is pointed out in [144], where a microgrid's frequency response is evaluated for different inertia constant values.

Although PV systems do not provide inertia to the grid, power electronics and a fast response storage system may help to synthetize inertia and therefore improve the system's resiliency [23], [145].

\section{Control actions on dispatchable units}

Typical control strategies for microgrids under various conditions are detailed in [7], [146] and an outstanding review is provided by [23]. Figure 17 shows the typical three-layer hierarchical control used in most systems to adjust the power and correct any deviations.

Among all of the primary controls developed in the literature, the droop-control method is by far the most commonly used and the easiest to implement. In large power systems, it is used to control units involved in primary regulation [140], [143]. Its use in microgrids is justified and detailed in [22], [147].

Any power imbalance is automatically compensated by the generation proportionally to the difference in active power $\Delta P=\Delta\left(P_{\text {gen }}-P_{\text {load }}\right)$. Each generator participates proportionally to its droop value $R_{\text {gen }}$ and its contribution is therefore $\Delta P_{\text {gen }}=R_{\text {gen }} * \Delta f$ (note that the generation remains limited by its ramp rate). Figure 18 shows how two units with different droop characteristics participate in the frequency regulation. 


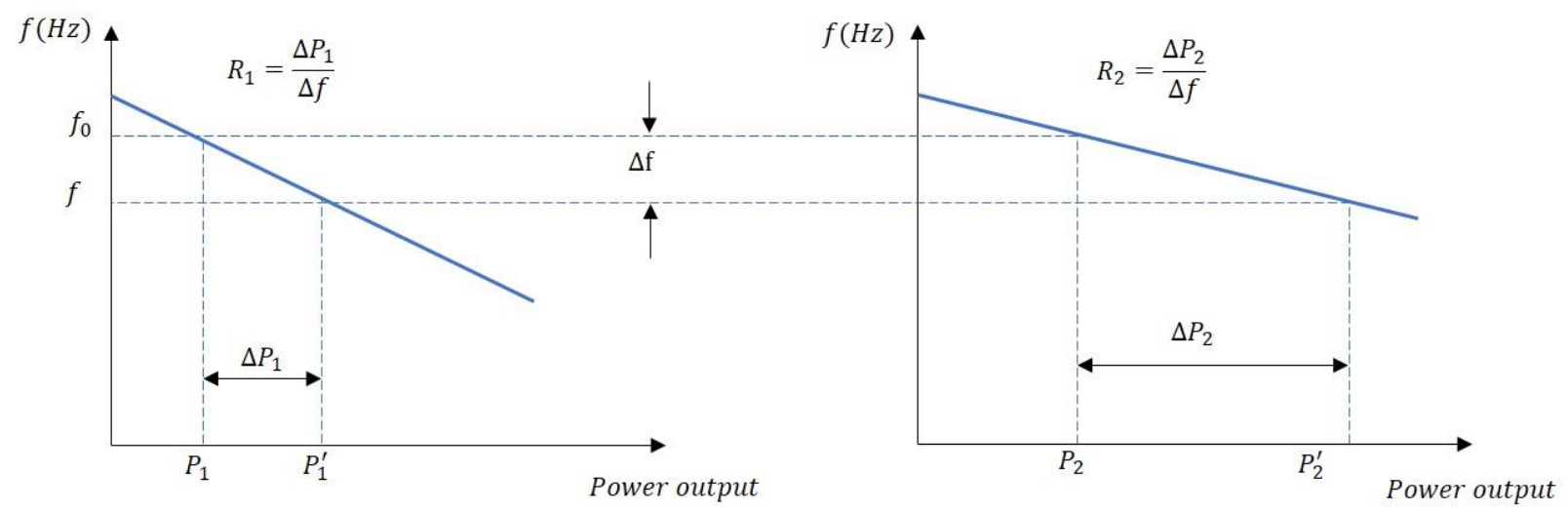

Figure 18 Control of two units with different droop characteristics [140].

The active power control is a common rule applied by all units that takes place in the primary response. However, controllers must embed additional features in order to prevent the equipment from going out of their operational range. This will be presented in the next sections.

\subsubsection{Control of fossil engines}

Fossil engines are naturally the main actors of power quality regulation. In most stability studies, the regulation potential is solely addressed using droop $R_{\text {gen }}$. But fossil units remain limited by their flexibility in terms of ramp and load factor (which justifies the study of their dynamical behavior as presented in part 2.2).

The control of fossil units and its simulation for stability studies will depend on the availability of information regarding the unit's transient behavior as well at its technical limitations (ramping range, power range, maximum fuel mass-flow, temperature limits, emissions limits, etc.). In order to model and study the electrical stability, only a high level of abstraction is generally possible due to lack of public information (see Figure 19).

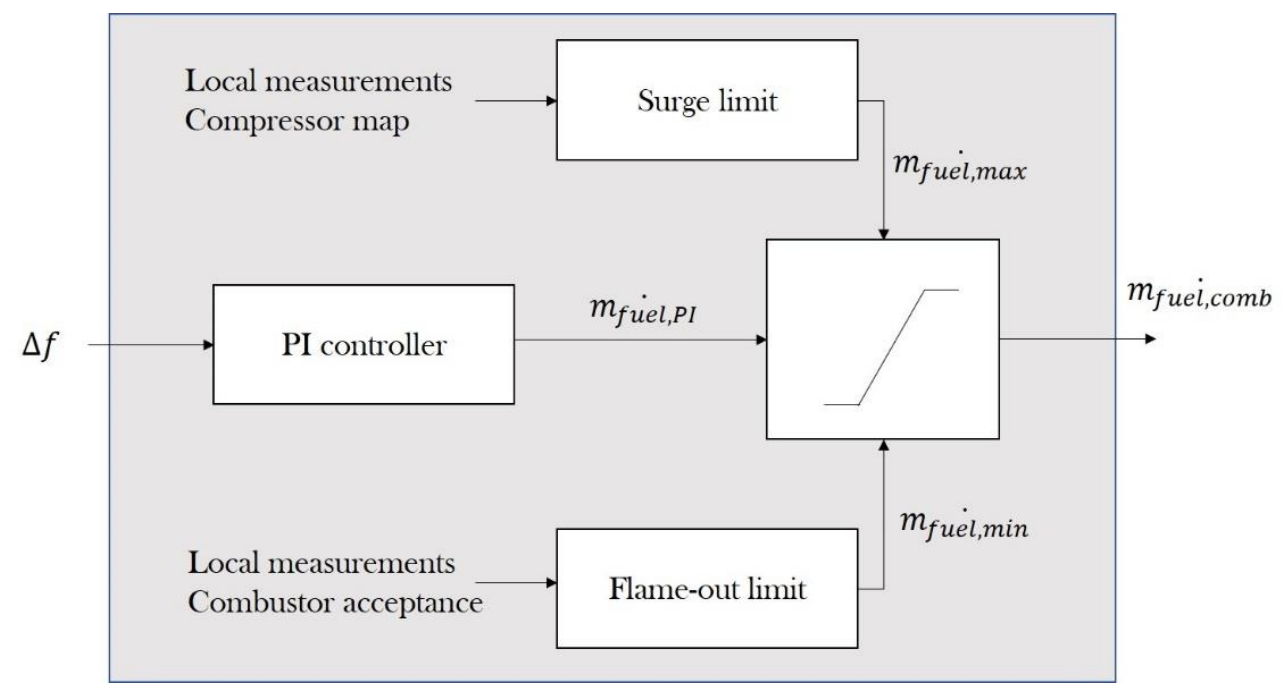

Figure 19 Principle of a multi-constrained fossil generation frequency controller

The control scheme may consist of a succession of saturation and time delays accounting for constraints and transient behavior, such as in the reduced order system frequency response model in [148] shown in Figure 20. This accounts for communication and injector time delays as well as the physical limits of minimum and maximum power. 


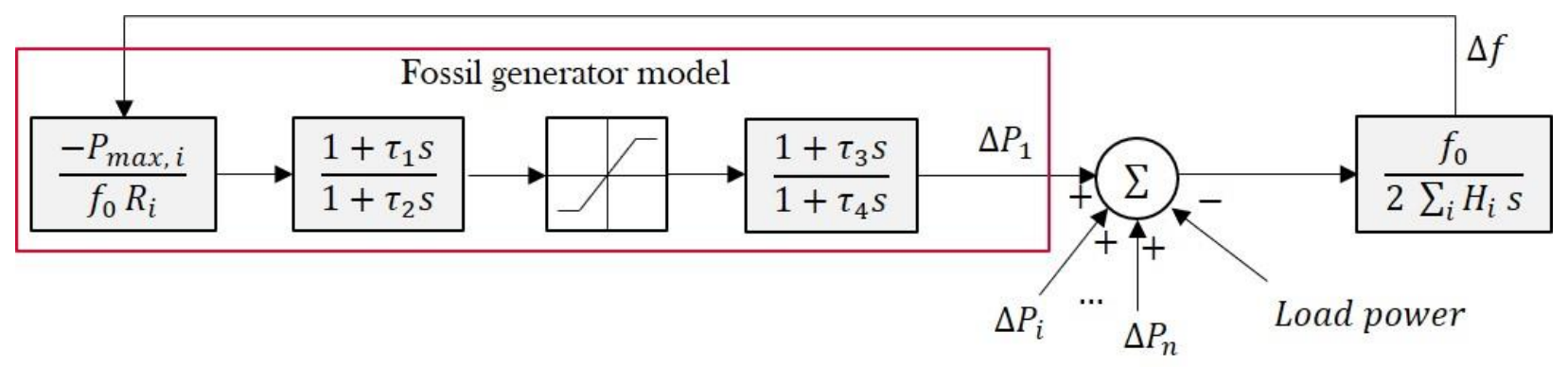

Figure 20 Reduced order frequency model accounting for gas turbine constraints and dynamics [148]

In Figure 20, and similarly to the control of conventional large-scale units, the power output is only driven by the droop characteristics and the frequency shift. However, in normal operations, the fossil generator needs to supply the power required by the user. The control signals of the load demand and frequency regulation are therefore summed to obtain the final power need by the generator[140].

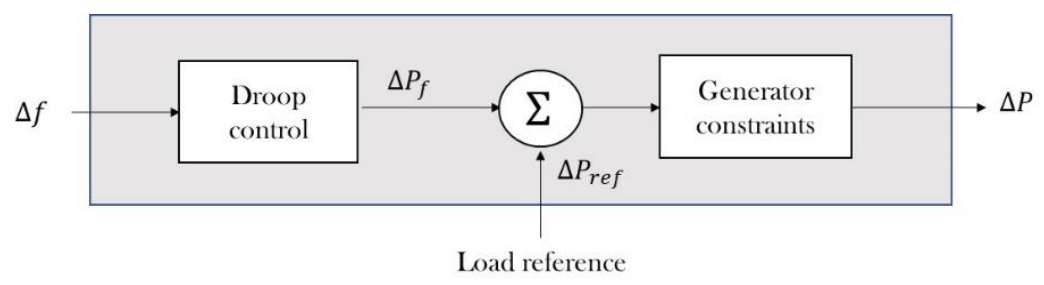

Figure 21 Coupled frequency-load setpoint regulation

\section{Control of gas turbines}

In ref [95], it is highlighted that a gas turbine's control system adjusts the power output while protecting the engines from excessive exhaust gas temperatures (turbine overheating), excessive speed and stress of rotating parts, and stalling and surging due to a high compressor ratio. Figure 19 gives a direct example for gas turbines: the fuel command depends on the frequency deviation, and is then saturated by the surge limit and flameout limit. This is applied in [102] to control the mass flow, which is a good methodology to include the physical limits of components in gas turbine power control. However, as pointed out in part 2.2, the knowledge required for modeling such control is rarely available and sometimes a simplified model has to be implemented (e.g., use of maximum and minimum ramp rates).

\section{Control of diesel engines}

Diesel control strategies and challenges regarding the plant's protection are stated in [24]. Similarly to gas turbines, the power demand of a diesel unit must take into account its limitations, such as the minimum loading factor, or its maximum achievable ramp rate. [118], [119] propose a diesel engine frequency control and show how an engine's characteristics may impact grid stability. In [118], the advantages of a highly flexible control for diesel allowing low loading are presented. The results show an improved stability margin for frequency and highlight the potential of low-load diesel technology to reduce storage capacity investments. As fossil units tend to be flexibility providers more than prime energy suppliers, low-load and highly flexible fossil unit control will probably be a key issue in the future.

\subsubsection{Control of storage systems}

Fast-discharging storage technologies are widely used for short-term regulation of power imbalances. An overview of control strategies for storage systems in given in [149]. In [150], an experimental study shows how droop-controlled storage can be used to regulate the system's frequency. 
As battery energy systems are increasingly common in microgrid applications, the literature covers a wide variety of control strategies. [149] introduce the concept of state-of-charge weighted droop control in order to adapt the regulation to the amount of energy remaining in the battery. Similarly to fossil engines, battery control systems include protections and saturation to take chemical dynamics and components' electrical limitations into account [151]. In [152], an ingenious control scheme is proposed to coordinate the frequency control of fossil units and storage systems.

Since control schemes must take the specificities of each technology into account, specific strategies are developed for flywheels [153] and super-capacitors [154].

\subsubsection{Control of load}

In high-reliability industrial applications, the continuity of supply is a priority. This leaves little potential for taking action on load in order to correct instabilities. Underfrequency load-shedding procedures must only be used in emergency situations in order to protect the grid from blackout [140]. It is however important to carefully design the load shedding to provide significant stability improvement [155]. If a significant share of load is considered as non-critical, it is possible to use it as a flexibility potential and regulate the frequency and voltage deviations [51], [156]. However, accurate load models are necessary to assess the potential of flexibility and stability improvements [157]. This solution is one of the most advantageous since no additional investment is necessary to integrate a large share of renewables.

\subsubsection{Participation of PV systems}

Unlike for wind generators, which have higher inertia and show some capacity for frequency and voltage regulation, PV generators are more limited when no storage is associated [158]. Depending on the inverter technology, the power factor can be adjusted and therefore participate in the voltage regulation. Using curtailment, it is also possible to regulate overfrequency events by lowering the power output of the inverter. This is detailed in [159], which presents an overview of the active power control of PV systems. The potential of PV plant curtailment has also been pointed out in [160] to lower the risks of short-term drops due to solar variability. By reducing the number of connected panels and therefore the available production, the potential solar drop is also reduced. This is however subject to high uncertainties related to the forecast of short-term variations. In addition, a significant part of the solar production is lost, which reduces the environmental and economic performance of the plant. This solution must therefore be put into perspective with other mitigation levers, such as storage systems, and should be evaluated at the sizing step.

When associated with a sufficient energy buffer with a very fast response time, grid-forming inverters can enhance the grid's stability with synthetic inertia. This also allows black start capability when a large share of renewables feed the system. An overview of grid-forming PV inverters from an operator, manufacturer and research perspective is provided in [161].

\subsubsection{Modeling of short-term control and power quality}

Modeling the short-term power control is mandatory to accurately assess a system's potential for renewable integration. Using voltage and frequency response modeling, the authors of [46] proved that the maximum renewable penetration limit to ensure grid reliability in Indonesia was 31\%. In [162], a transient stability method is used to determine the maximum intermittent power penetration in an isolated system. Using swing equation equal area criteria, the ability of a system to properly control active power during transient events is studied in [163]. Numerous commercial software applications now allow stability studies featuring renewable technologies (ETAP, MATLAB, PSCAD, OPEN-DSS) and are widely used in both academic and industrial environments. Finally, research programs increasingly work on simulating systems in real time using hardwarein-the loop techniques [164]. 
By running simulations over a long period of time, it is possible to assess the performance of the microgrid in terms of quality of supply through reliability indicators [32] such as EENS, CAIDI, ASAI, and ASUI. This study gives an example of how to assess the reliability level in several plant configurations (islanded vs gridconnected, various sizes of PV systems and storage). Thanks to power quality simulation, probabilities of electricity outages (underfrequency load-shedding or grid blackouts) can be identified and thus integrated in the reliability assessment. This issue has been partly addressed in a previous work based on the duration of overfrequency and underfrequency regimes over one day [165]. Deeper investigations need to be carried out to propose a methodology to evaluate the reliability indicators related to power quality problems. Figure 22 proposes such a procedure for the reliability assessment of an industrial microgrid with renewable integration.

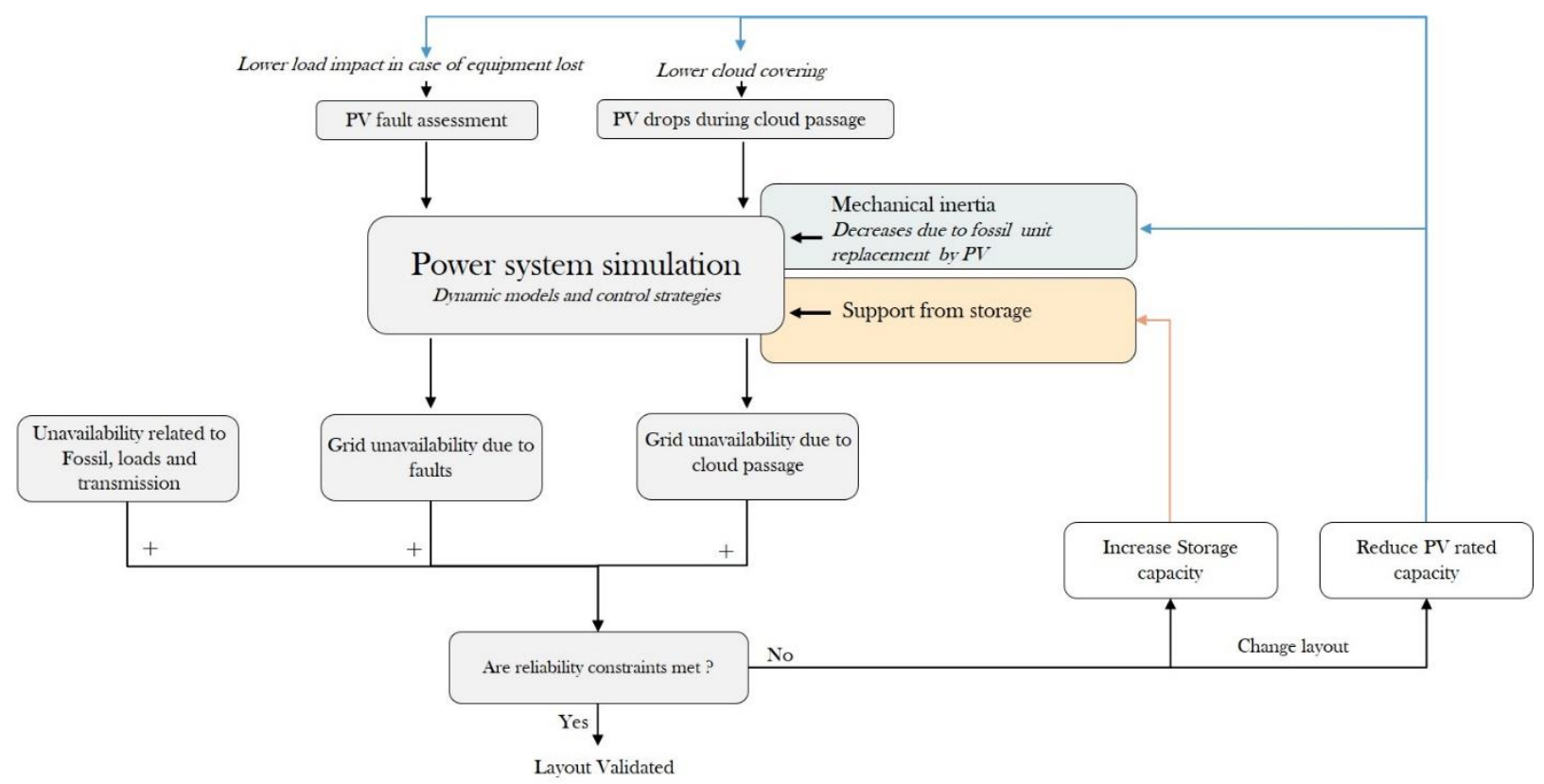

Figure 22 Example of a procedure for reliability assessment over a microgrid layout (where decisions are made on PV and storage capacities)

\subsection{The energy management approach}

Although power control is very important for grid stability and robustness, it does not deal with economic objectives or handle forecasts of load and renewable resources. The economic performance of the power system involves ensuring the global equilibrium of production and consumption while minimizing the overall operational costs and meeting important constraints such as emissions reduction. An Energy Management System (EMS) ensures the proper allocation of production units by monitoring data and collecting forecasts. Considering industrial microgrid characteristics, centralized EMS generally seems more convenient [8].

The efficient performance of EMS lies in its ability to allocate the resources of each device at a minimal cost, which means that its dispatch algorithm is of paramount importance. In [19], [20], detailed surveys of energy management methods are proposed. 
Table 5 Comparative review of energy management optimization techniques

\begin{tabular}{|l|l|l|l|l|}
\hline $\begin{array}{l}\text { Optimization } \\
\text { family }\end{array}$ & Principle & References & Advantages \\
\hline $\begin{array}{l}\text { Rule-based \& } \\
\text { progamic }\end{array}$ & $\begin{array}{l}\text { Logical decisions } \\
\text { \& flow diagrams }\end{array}$ & {$[166],[167]$} & $\begin{array}{l}\text { Comprehensive } \\
\text { framework } \\
\text { Close description } \\
\text { of expert } \\
\text { knowledge }\end{array}$ & $\begin{array}{l}\text { Lack of flexibility } \\
\text { and reproducibility } \\
\text { Hard to implement } \\
\text { for complex systems }\end{array}$ \\
\hline $\begin{array}{l}\text { Artificial } \\
\text { intelligence }\end{array}$ & $\begin{array}{l}\text { Machine learning } \\
\text { based on large } \\
\text { datasets }\end{array}$ & {$[168],[169]$} & $\begin{array}{l}\text { Large number of } \\
\text { situations } \\
\text { handled }\end{array}$ & $\begin{array}{l}\text { No comprehensive } \\
\text { description } \\
\text { Lack of reliability } \\
\text { certification }\end{array}$ \\
\hline Meta-heuristics & $\begin{array}{l}\text { Optimization } \\
\text { using bee-colony, } \\
\text { genetic algorithms, } \\
\text { etc. }\end{array}$ & {$[170]-[172]$} & $\begin{array}{l}\text { Comprehensive } \\
\text { optimization } \\
\text { framework with } \\
\text { non-linear } \\
\text { modeling } \\
\text { capabilities }\end{array}$ & $\begin{array}{l}\text { No guarantee of } \\
\text { optimality }\end{array}$ \\
\hline $\begin{array}{l}\text { Linear } \\
\text { programming }\end{array}$ & $\begin{array}{l}\text { Optimization } \\
\text { based on linear } \\
\text { description of } \\
\text { objective functions } \\
\text { and constraints }\end{array}$ & {$[148],[173]-[179]$} & $\begin{array}{l}\text { Guarantee of } \\
\text { optimality } \\
\text { Easy } \\
\text { implementation } \\
\text { Fast-running } \\
\text { commercial } \\
\text { solvers }\end{array}$ & $\begin{array}{l}\text { Requires relatively } \\
\text { high level of } \\
\text { abstraction } \\
\text { Lower performance } \\
\text { of non-linear and } \\
\text { non-convex } \\
\text { description }\end{array}$ \\
\hline $\begin{array}{l}\text { Multi-layer } \\
\text { optimization }\end{array}$ & $\begin{array}{l}\text { Predictive control } \\
\text { model }\end{array}$ & {$[55],[180]-[185]$} & $\begin{array}{l}\text { Ability to enable } \\
\text { different levels of } \\
\text { abstraction with } \\
\text { high fidelity } \\
\text { model } \\
\text { High modularity } \\
\text { and flexibility to } \\
\text { describe the } \\
\text { problem }\end{array}$ & $\begin{array}{l}\text { Need to build a } \\
\text { specific framework } \\
\text { for each application }\end{array}$ \\
\hline
\end{tabular}

Linear programming (LP) and multi-layer optimization techniques turn out to be very relevant to address reliability and power quality in industrial energy management problems. This is why a special focus is proposed in this paper.

\section{Linear programming, robust and stochastic optimization}

EMS protects the grid from unexpected events (severe loss of renewable generation, a generator contingency or an increase in load) by implementing the concept of spinning reserve, the $\mathrm{N}+1$ rule, or even an aggregated indicator for a frequency shift. In reference [148], the challenges of a frequency-constrained model are 
developed. The possible options to directly integrate frequency shift mitigation lead to either a non-linear problem or a sub-optimal solution (use of minimum ramping capacity, minimum value of inertia, etc.).

Deterministic LP approaches such as described above are easy to implement, yet insufficient to handle reliability and power quality, since transients are caused by unplanned renewable losses and generator contingencies. A stochastic approach can deal with probabilistic forecasts and is therefore convenient to address renewables' prediction uncertainties. However, the complexity of the problem is significantly increased, and this approach does not guarantee a fully reliable solution. A stochastic approach is most relevant when a tradeoff can be made between reliability penalties and operational savings. The authors in [179] propose a two-stage stochastic MILP* formulation to calculate both unit commitment and reserve scheduling with $0-\mathrm{Hz}$ and $+/-10 \mathrm{MHz}$ of tolerance for frequency deviation. In [175], the frequency control is integrated into the EMS, but this significantly increases the complexity of the problem. A Benders decomposition is therefore used to solve the problem.

A robust approach is useful when reliability constraints play an important role in the operation, and avoids the use of probabilistic forecasts thanks to an efficient selection of uncertainty scenarios [174]. Uncertainty is addressed from a conservative point of view involving a study of the historical performance of the forecast system. This can be a challenge if no historical data are available at the plant's location.

\section{Model predictive control (MPC) for energy management systems}

As pointed out in [181], a fully-integrated MILP model problem accounting for uncertainties and reliability can be very hard to solve due to the number of variables and constraints. This justifies the use of modelpredictive control (or a multi-layer approach) to address both control and management of the microgrid.

As presented in [183], model predictive control for energy management consists of a predictive model that plans optimal energy exchanges based on forecasts, and a system model that performs the dispatch and controls the power flux. The predictive model can be based on various management techniques such as presented above. The level of accuracy of the system model can be adapted to available information and may embed a very detailed control scheme. Finally, MPC reproduces the hierarchical relationship of the energy and power management system in real-life conditions.

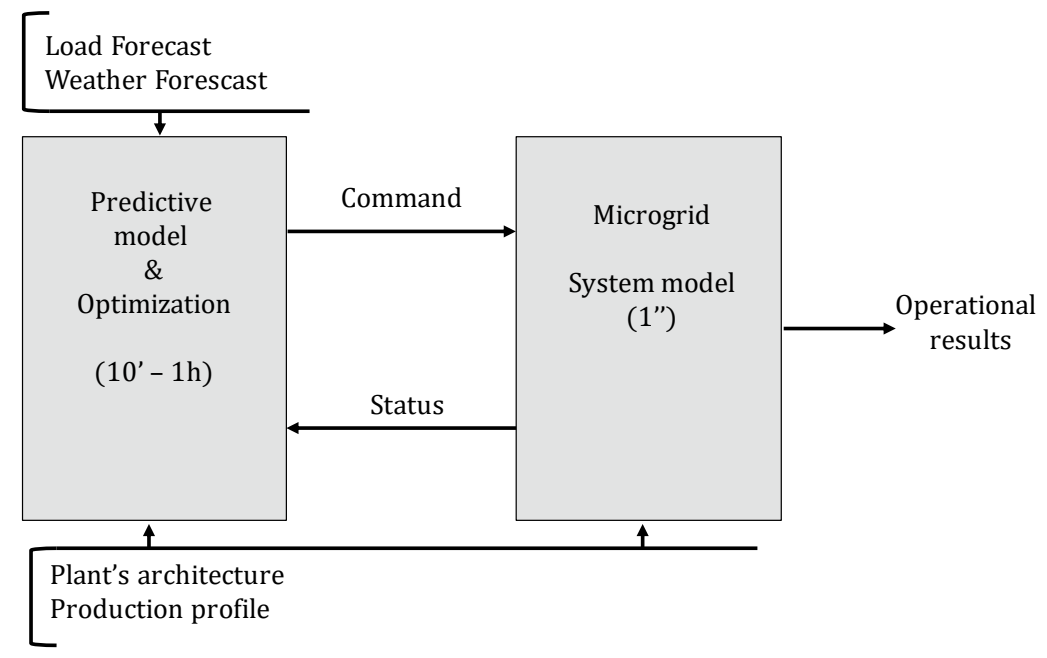

\footnotetext{
* Mixed-Interger Linear Programming
} 
Figure 23 Architecture of model predictive control for energy management

The predictive model can be divided into two layers in order to perform a high-level economic evaluation and continuously track the optimal operation. In [185], MPC is used to model a DC low voltage microgrid. In [55], two-layer model predictive control is used to simulate an off-grid O\&G platform fed by a wind farm, two gas turbines and battery storage.

In [180], [181], [184], the high level optimization problem is addressed using linear programming and therefore reproduces the decision of an LP-based energy management system. The results show that the method is able to handle forecast uncertainties, simulate dynamic behavior with accuracy, and improve both renewable penetration and operational savings.

\section{Discussion and main findings}

In this paper, we detailed the concept of industrial microgrids along with some key characteristics. This brings a new field of application for microgrids to add to those previously detailed in [8], [27], [28]. Additionally, we provided a review of renewable integration studies in $O \& G$ systems to illustrate the main challenges of industrial microgrids, which is a topic that has not been addressed in existing review papers.

The reliability of PV systems was found to be widely covered by previous literature reviews [59]. However, we identified gaps on the evaluation of solar variability. Based on previous work gathering studies on variability quantifiers [71], and solar forecasting [78], we presented state-of-the art techniques to evaluate PV power dynamics. Considering the size of industrial microgrids, we focused on large-scale PV systems, stressing the need for geographical smoothing models.

The economic and environmental performances of industrial microgrids are closely related to the performances of fossil generators. However, while the review studies provide a wide variety of models and tools [101], [110], they do not focus on the assessment of fossil unit performances in dynamic operations and cloud passage. This paper therefore reviewed dynamical modeling techniques to improve the performance assessment. The impact of dynamic operation on reliability and lifetime reduction remains an open question after this study as this issue has been poorly addressed in the literature.

Most of the review studies handle a single aspect of the performance of microgrids by covering either reliability aspects related to short-term power control [23]or energy management optimization [19]. In this study, both concepts have been addressed to draw attention to the link between these two operational layers. Similarly to [166], we put the focus on the control strategies of each component and also more deeply cover power quality aspects to provide pathways for a reliability assessment involving several microgrid configurations and renewable integration scenarios. Thanks to this analysis, the main goal of power quality simulation in industrial microgrids may be defined as follows: to evaluate the risks of loss of electricity supply given a certain level of PV penetration whilst properly considering the support role of fossil generators, storage, loads and inverters.

Lastly, we identified the most relevant energy management techniques for industrial microgrids. Previous review studies have provided a complete overview of energy management techniques and mathematical formulations [19], [20]. Since reliability is a key aspect of industrial microgrids, this paper provided an overview of reliability and power quality constraints formulations, and robust energy management, and highlighted the potential of model predictive control for better ensuring the link between cost optimization and power quality control. 


\section{Conclusion}

This paper provided a review of the main challenges of solar PV integration into industrial microgrids under reliability constraints. The need for continuous operation of industrial power plants requires high availability of electrical generation. On the other hand, the electrical system is more vulnerable due to its low inertia and low flexibility compared to large grids or residential systems with electrical loads that are likely to be shed or delayed. The integration of highly variable and stochastic solar power challenges the performance and reliability of power plants as the rapid power losses involved can cause considerable electrical instabilities.

This calls for a more extensive understanding of the short-term behavior of renewable systems to anticipate extreme events. Variability analysis techniques have been developed to quantify solar ramps and can be coupled with a geographic smoothing model in order to assess the power fluctuation of the overall solar plant. The availability of high resolution time-series remains a challenge, especially in isolated areas. In the future, techniques to increase the granularity of satellite observations and forecasts to capture local and short-term variability will be key factors of success for isolated microgrids.

A particular feature of large-scale microgrids is their use of fossil generators. The integration of renewable energy sources therefore requires a change in the operational approach. Consequently, conventional modeling and optimization tools that were designed for static operations need to evolve, as fuel consumption, fatigue and emissions could significantly diverge from historic benchmarks. The development of tools to model fossil generation dynamics is crucial to carry out a proper techno-economic analysis of a plant and ensure availability.

Control and management schemes must be chosen in order to correspond to this highly constrained framework. The large number of non-linearities (solar ramps, electrical instabilities, fuel consumption, etc.) as well as the role of the control scheme call for the integration of a detailed description of the electrical system in future techno-economic studies. Optimization techniques should therefore integrate these phenomena into their equations while maintaining the ability to identify the most economical solution. Model predictive control coupled with linear programming tends to be the best compromise considering the current state-of-the-art.

Finally, the sizing of microgrids is also a topic of paramount importance and has already been the focus of numerous studies. Sizing that addresses reliability constraints is studied in references [186]-[188] along with the uncertainty of solar production [189]-[192], but a deeper study is necessary to identify the most suitable techniques for industrial micro grids. Such an analysis remains a perspective for this work.

\section{References}

[1] United Nations General Assembly, "Political declaration of the high-level political forum on sustainable development convened under the auspices of the General Assembly," presented at the Sustainable Development Goals Summit, New York, Oct. 2019.

[2] UNFCCC Communications, "COP25 to Be the Launchpad for Significantly more Climate Ambition | UNFCCC,” Nov. 29, 2019. https:/unfccc.int/news/cop25-to-be-the-launchpad-for-significantlymore-climate-ambition-0 (accessed Mar. 09, 2020).

[3] IEA, World Energy Outlook 2018. IEA Publications, 2018.

[4] IEA, "Tracking Industry," IEA, Paris, May 2019. Accessed: Apr. 23, 2019. [Online]. Available: https://www.iea.org/reports/tracking-industry 
[5] J. Rissman et al., "Technologies and policies to decarbonize global industry: Review and assessment of mitigation drivers through 2070," Appl. Energy, vol. 266, p. 114848, May 2020, doi: 10.1016/j.apenergy.2020.114848.

[6] P. Alby, J.-J. Dethier, and S. Straub, "Firms Operating under Electricity Constraints in Developing Countries," World Bank Econ. Rev., vol. 27, no. 1, pp. 109-132, 2013.

[7] N. Hatziargyriou, Ed., Microgrids: architectures and control. Chichester: Wiley-IEEE Press, 2014.

[8] G. Guerassimoff, Microgrids : pourquoi, pour qui ? Presses des Mines, 2017. [Online]. Available: https://hal-mines-paristech.archives-ouvertes.fr/hal-01589804

[9] "Eigg Electric,” The Isle of Eigg. http://isleofeigg.org/eigg-electric/ (accessed Mar. 10, 2020).

[10] Berkeley Lab, "UCSD | Building Microgrid,” Microgrids at Berkeley Lab. https://buildingmicrogrid.lbl.gov/ucsd (accessed Mar. 10, 2020).

[11] P. Bornard, "Conduite d'un système de production-transport," Tech. Ing. Réseaux Électr. Transp. Répart., vol. base documentaire: TIB263DUO., no. ref. article : d4080, 2000, [Online]. Available: https://www.techniques-ingenieur.fr/base-documentaire/energies-th4/reseaux-electriques-detransport-et-de-repartition-42263210/conduite-d-un-systeme-de-production-transport-d4080/

[12] J. Lian, Y. Zhang, C. Ma, Y. Yang, and E. Chaima, "A review on recent sizing methodologies of hybrid renewable energy systems," Energy Convers. Manag., vol. 199, p. 112027, Nov. 2019, doi: 10.1016/j.enconman.2019.112027.

[13] K. Anoune, M. Bouya, A. Astito, and A. B. Abdellah, "Sizing methods and optimization techniques for PV-wind based hybrid renewable energy system: A review," Renew. Sustain. Energy Rev., vol. 93, pp. 652-673, Oct. 2018, doi: 10.1016/j.rser.2018.05.032.

[14] S. Sinha and S. S. Chandel, "Review of software tools for hybrid renewable energy systems," Renew. Sustain. Energy Rev., vol. 32, pp. 192-205, Apr. 2014, doi: 10.1016/j.rser.2014.01.035.

[15] HOMER Energy, "HOMER - Hybrid Renewable and Distributed Generation System Design Software.” https://www.homerenergy.com/ (accessed Mar. 19, 2019).

[16] Berkeley Lab, "Distributed Energy Resources - Customer Adoption Model (DER-CAM) | Building Microgrid.” https://building-microgrid.lbl.gov/projects/der-cam (accessed Mar. 19, 2019).

[17] C. N. R. NRCAN, "RETScreen, clean energy management software," Mar. 10, 2010. https:/www.nrcan.gc.ca/maps-tools-publications/tools/data-analysis-softwaremodelling/retscreen/7465 (accessed Apr. 07, 2020).

[18] S. Jayashree and K. Malarvizhi, "Methodologies for Optimal Sizing of Battery Energy Storage in Microgrids: A Comprehensive Review," in 2020 International Conference on Computer Communication and Informatics (ICCCI), Jan. 2020, pp. 1-5. doi: 10.1109/ICCCI48352.2020.9104131.

[19] M. F. Zia, E. Elbouchikhi, and M. Benbouzid, "Microgrids energy management systems: A critical review on methods, solutions, and prospects," Appl. Energy, vol. 222, pp. 1033-1055, Jul. 2018, doi: 10.1016/j.apenergy.2018.04.103.

[20] A. Ahmad Khan, M. Naeem, M. Iqbal, S. Qaisar, and A. Anpalagan, "A compendium of optimization objectives, constraints, tools and algorithms for energy management in microgrids," Renew. Sustain. Energy Rev., vol. 58, pp. 1664-1683, May 2016, doi: 10.1016/j.rser.2015.12.259.

[21] C. I. Ossai, "Optimal renewable energy generation - Approaches for managing ageing assets mechanisms," Renew. Sustain. Energy Rev., vol. 72, pp. 269-280, May 2017, doi: 10.1016/j.rser.2017.01.041.

[22] U. B. Tayab, M. A. B. Roslan, L. J. Hwai, and M. Kashif, "A review of droop control techniques for microgrid,” Renew. Sustain. Energy Rev., vol. 76, pp. 717-727, Sep. 2017, doi: 10.1016/j.rser.2017.03.028.

[23] D. E. Olivares et al., "Trends in Microgrid Control," IEEE Trans. Smart Grid, vol. 5, no. 4, pp. 19051919, Jul. 2014, doi: 10.1109/TSG.2013.2295514.

[24] F. Katiraei, K. Mauch, M. Vandenbergh, and L. Arribas, "PV Hybrid Mini-Grids: Applicable Control Methods for Various Situations," IEA, 2012. 
[25] M. Farrokhabadi et al., "Microgrid Stability Definitions, Analysis, and Examples," IEEE Trans. Power Syst., vol. 35, no. 1, pp. 13-29, Jan. 2020, doi: 10.1109/TPWRS.2019.2925703.

[26] A. Cagnano, E. De Tuglie, and P. Mancarella, "Microgrids: Overview and guidelines for practical implementations and operation," Appl. Energy, vol. 258, p. 114039, Jan. 2020, doi: 10.1016/j.apenergy.2019.114039.

[27] S. Parhizi, H. Lotfi, A. Khodaei, and S. Bahramirad, "State of the Art in Research on Microgrids: A Review,” IEEE Access, vol. 3, pp. 890-925, 2015, doi: 10.1109/ACCESS.2015.2443119.

[28] A. Hirsch, Y. Parag, and J. Guerrero, "Microgrids: A review of technologies, key drivers, and outstanding issues," Renew. Sustain. Energy Rev., vol. 90, pp. 402-411, Jul. 2018, doi: 10.1016/j.rser.2018.03.040.

[29] ARENA, "Weipa solar farm - Australian Renewable Energy Agency (ARENA)," Australian Renewable Energy Agency. https://arena.gov.au/projects/weipa-solar-farm/ (accessed Apr. 23, 2019).

[30] L. Riboldi and L. Nord, "Offshore Power Plants Integrating a Wind Farm: Design Optimisation and Techno-Economic Assessment Based on Surrogate Modelling,” Processes, vol. 6, no. 12, p. 249, Dec. 2018, doi: 10.3390/pr6120249.

[31] M. E. Hamedani Golshan, M. A. S. Masoum, and S. Y. Derakhshandeh, "Profit-based unit commitment with security constraints and fair allocation of cost saving in industrial microgrids," IET Sci. Meas. Technol., vol. 7, no. 6, pp. 315-325, Nov. 2013, doi: 10.1049/iet-smt.2013.0044.

[32] S. M. Nosratabadi, R.-A. Hooshmand, E. Gholipour, and S. Rahimi, "Modeling and simulation of long term stochastic assessment in industrial microgrids proficiency considering renewable resources and load growth," Simul. Model. Pract. Theory, vol. 75, pp. 77-95, Jun. 2017, doi: 10.1016/j.simpat.2017.03.013.

[33] M. Soshinskaya, W. H. J. Crïns-Graus, J. van der Meer, and J. M. Guerrero, "Application of a microgrid with renewables for a water treatment plant," Appl. Energy, vol. 134, pp. 20-34, Dec. 2014, doi: 10.1016/j.apenergy.2014.07.097.

[34] V. Subramanyam, T. Jin, and C. Novoa, "Sizing a renewable microgrid for flow shop manufacturing using climate analytics," J. Clean. Prod., vol. 252, p. 119829, Apr. 2020, doi: 10.1016/j.jclepro.2019.119829.

[35] Aria, "Base Aria: Perturbation d'alimentation électrique," Ministère du Développement Durable, 2009. [Online]. Available: https://www.aria.developpement-durable.gouv.fr/wpcontent/uploads/2013/07/09-10-analogies_perturbations_electrique.pdf

[36] "IEEE Recommended Practice for the Design of Reliable Industrial and Commercial Power Systems,” IEEE Std 493-2007 Revis. IEEE Std 493-1997, pp. 1-383, Jun. 2007, doi: 10.1109/IEEESTD.2007.380668.

[37] M. Krasich, "How to estimate and use MTTF/MTBF would the real MTBF please stand up?," in 2009 Annual Reliability and Maintainability Symposium, Jan. 2009, pp. 353-359. doi: 10.1109/RAMS.2009.4914702.

[38] H. Haes Alhelou, M. E. Hamedani-Golshan, T. C. Njenda, and P. Siano, "A Survey on Power System Blackout and Cascading Events: Research Motivations and Challenges," Energies, vol. 12, no. 4, Art. no. 4, Jan. 2019, doi: 10.3390/en12040682.

[39] M. A. Cole, R. J. R. Elliott, G. Occhiali, and E. Strobl, "Power outages and firm performance in SubSaharan Africa," J. Dev. Econ., vol. 134, pp. 150-159, Sep. 2018, doi: 10.1016/j.jdeveco.2018.05.003.

[40] H. A. Pasha, A. Ghaus, and S. Malik, "The economic cost of power outages in the industrial sector of Pakistan,” Energy Econ., vol. 11, no. 4, pp. 301-318, Oct. 1989, doi: 10.1016/0140-9883(89)900467.

[41] S. Mashayekh et al., "Security-Constrained Design of Isolated Multi-Energy Microgrids," IEEE Trans. Power Syst., vol. 33, no. 3, pp. 2452-2462, May 2018, doi: 10.1109/TPWRS.2017.2748060.

[42] O. Erdinc, N. G. Paterakis, and J. P. S. Catalão, "Overview of insular power systems under increasing penetration of renewable energy sources: Opportunities and challenges,” Renew. Sustain. Energy Rev., vol. 52, pp. 333-346, Dec. 2015, doi: 10.1016/j.rser.2015.07.104. 
[43] N. Maïzi et al., "Maximizing intermittency in 100\% renewable and reliable power systems: A holistic approach applied to Reunion Island in 2030,” Appl. Energy, vol. 227, pp. 332-341, Oct. 2018, doi: 10.1016/j.apenergy.2017.08.058.

[44] W. W. Anderson and O. A. Yakimenko, "Comparative analysis of two microgrid solutions for island green energy supply sustainability," in 2017 IEEE 6th International Conference on Renewable Energy Research and Applications (ICRERA), Nov. 2017, pp. 245-250. doi: 10.1109/ICRERA.2017.8191274.

[45] S. Favuzza et al., "An Analysis of the Intertial Response of Small Isolated Power Systems in Presence of Generation from Renewable Energy Sources," in 2018 IEEE 4th International Forum on Research and Technology for Society and Industry (RTSI), Palermo, Sep. 2018, pp. 1-6. doi: 10.1109/RTSI.2018.8548401.

[46] K. M. Banjar-Nahor, L. Garbuio, V. Debusschere, N. Hadjsaid, T.-T.-H. Pham, and N. Sinisuka, "Study on Renewable Penetration Limits in a Typical Indonesian Islanded Microgrid Considering the Impact of Variable Renewables Integration and the Empowering Flexibility on Grid Stability," in 2018 IEEE PES Innovative Smart Grid Technologies Conference Europe (ISGT-Europe), Sarajevo, Bosnia and Herzegovina, Oct. 2018, pp. 1-6. doi: 10.1109/ISGTEurope.2018.8571673.

[47] IRENA, “Innovation Outlook: Renewable: Mini-grids,” p. 184, 2016.

[48] X. Liang, "Emerging Power Quality Challenges Due to Integration of Renewable Energy Sources," IEEE Trans. Ind. Appl., vol. 53, no. 2, pp. 855-866, Mar. 2017, doi: 10.1109/TIA.2016.2626253.

[49] M. S. Masnadi et al., "Global carbon intensity of crude oil production," Science, vol. 361, no. 6405, pp. 851-853, Aug. 2018, doi: 10.1126/science.aar6859.

[50] OGCI, “A report from the Oil and Gas Climate Initiative,” Sep. 2018.

[51] E. Alves, S. Sanchez, D. Brandao, and E. Tedeschi, "Smart Load Management with Energy Storage for Power Quality Enhancement in Wind-Powered Oil and Gas Applications,” p. 15, 2019.

[52] J. Wang, J. O’Donnell, and A. R. Brandt, "Potential solar energy use in the global petroleum sector," Energy, vol. 118, pp. 884-892, Jan. 2017, doi: 10.1016/j.energy.2016.10.107.

[53] M. Absi Halabi, A. Al-Qattan, and A. Al-Otaibi, "Application of solar energy in the oil industryCurrent status and future prospects," Renew. Sustain. Energy Rev., vol. 43, pp. 296-314, Mar. 2015, doi: 10.1016/j.rser.2014.11.030.

[54] A. R. Ardal, K. Sharifabadi, O. Bergvoll, and V. Berge, "Challenges with integration and operation of offshore oil \&amp; gas platforms connected to an offshore wind power plant," in 2014 Petroleum and Chemical Industry Conference Europe, Amsterdam, Netherlands, Jun. 2014, pp. 1-9. doi: 10.1109/PCICEurope.2014.6900054.

[55] L. Bigarelli, A. Lidozzi, M. di Benedetto, L. Solero, and S. Bifaretti, "Model Predictive Energy Management for Sustainable Off-Shore Oil and Gas Platforms," in 2019 21st European Conference on Power Electronics and Applications (EPE '19 ECCE Europe), Genova, Italy, Sep. 2019, p. P.1P.10. doi: 10.23919/EPE.2019.8914962.

[56] D. Hu, X. Zhao, Xu Cai, and Jianfeng Wang, "Impact of wind power on stability of offshore platform power systems," in 2008 Third International Conference on Electric Utility Deregulation and Restructuring and Power Technologies, Nanjing, China, Apr. 2008, pp. 1688-1692. doi: 10.1109/DRPT.2008.4523677.

[57] A. R. Årdal, S. D’Arco, R. E. Torres-Olguin, T. Undeland, and K. Shrarifabadi, "Parametric sensitivity of transients in an islanded system with an offshore wind farm connected to an oil platform," p. 10.

[58] N. Anglani, S. R. D. Salvo, G. Oriti, and A. L. Julian, "Renewable Energy Sources and Storage Integration in Offshore Microgrids," in 2020 IEEE International Conference on Environment and Electrical Engineering and 2020 IEEE Industrial and Commercial Power Systems Europe (EEEIC / I CPS Europe), Jun. 2020, pp. 1-6. doi: 10.1109/EEEIC/ICPSEurope49358.2020.9160760.

[59] P. Zhang, W. Li, S. Li, Y. Wang, and W. Xiao, "Reliability assessment of photovoltaic power systems: Review of current status and future perspectives," Appl. Energy, vol. 104, pp. 822-833, Apr. 2013, doi: 10.1016/j.apenergy.2012.12.010. 
[60] A. Sangwongwanich, Y. Yang, D. Sera, F. Blaabjerg, and D. Zhou, "On the Impacts of PV Array Sizing on the Inverter Reliability and Lifetime," IEEE Trans. Ind. Appl., vol. 54, no. 4, pp. 36563667, Jul. 2018, doi: 10.1109/TIA.2018.2825955.

[61] A. Dobos, "PVWatts Version 5 Manual," NREL/TP-6A20-62641, 1158421, Sep. 2014. doi: $10.2172 / 1158421$.

[62] G. N. Tiwari, A. K. Tiwari, and Shyam, Handbook of Solar Energy: Theory, Analysis and Applications. Singapore: Springer Singapore, 2016.

[63] M. Sengupta and A. Andreas, "Oahu Solar Measurement Grid (1-Year Archive): 1-Second Solar Irradiance; Oahu, Hawaii (Data).” 2010. doi: 10.5439/1052451.

[64] J. Stein, C. Hansen, and M. J. Reno, "The variability index: A new and novel metric for quantifying irradiance and PV output variability.," Sandia National Laboratories, 2012.

[65] R. Blaga and M. Paulescu, "Quantifiers for the solar irradiance variability: A new perspective," Sol. Energy, vol. 174, pp. 606-616, Nov. 2018, doi: 10.1016/j.solener.2018.09.034.

[66] M. Lave, "Solar variability zones: Satellite-derived zones that represent high-frequency ground variability," Sol. Energy, p. 10, 2017.

[67] P. Lauret, R. Perez, L. Mazorra Aguiar, E. Tapachès, H. M. Diagne, and M. David, "Characterization of the intraday variability regime of solar irradiation of climatically distinct locations," Sol. Energy, vol. 125, pp. 99-110, Feb. 2016, doi: 10.1016/j.solener.2015.11.032.

[68] A. Mills et al., "Dark Shadows," IEEE Power Energy Mag., vol. 9, no. 3, pp. 33-41, May 2011, doi: 10.1109/MPE.2011.940575.

[69] D. Cormode, A. D. Cronin, W. Richardson, A. T. Lorenzo, A. E. Brooks, and D. N. DellaGiustina, "Comparing ramp rates from large and small PV systems, and selection of batteries for ramp rate control," in 2013 IEEE 39th Photovoltaic Specialists Conference (PVSC), Tampa, FL, USA, Jun. 2013, pp. 1805-1810. doi: 10.1109/PVSC.2013.6744493.

[70] J. Marcos, L. Marroyo, E. Lorenzo, D. Alvira, and E. Izco, "From irradiance to output power fluctuations: the PV plant as a low pass filter," Prog. Photovolt. Res. Appl., vol. 19, no. 5, pp. 505510, 2011, doi: 10.1002/pip.1063.

[71] T. E. Hoff and R. Perez, "Quantifying PV power Output Variability," Sol. Energy, vol. 84, no. 10, pp. 1782-1793, Oct. 2010, doi: 10.1016/j.solener.2010.07.003.

[72] R. van Haaren, M. Morjaria, and V. Fthenakis, "Empirical assessment of short-term variability from utility-scale solar PV plants: Assessment of variability from utility-scale solar PV plants," Prog. Photovolt. Res. Appl., vol. 22, no. 5, pp. 548-559, May 2014, doi: 10.1002/pip.2302.

[73] M. Lave, J. Kleissl, and J. S. Stein, "A Wavelet-Based Variability Model (WVM) for Solar PV Power Plants," IEEE Trans. Sustain. Energy, vol. 4, no. 2, pp. 501-509, Apr. 2013, doi: 10.1109/TSTE.2012.2205716.

[74] Sandia University, "PV Performance Modeling Collaborative | Wavelet Variability Model,” 2012. https://pvpmc.sandia.gov/applications/wavelet-variability-model/ (accessed Mar. 23, 2020).

[75] J. M. Bright, C. J. Smith, P. G. Taylor, and R. Crook, "Stochastic generation of synthetic minutely irradiance time series derived from mean hourly weather observation data," Sol. Energy, vol. 115, pp. 229-242, May 2015, doi: 10.1016/j.solener.2015.02.032.

[76] C. M. Fernández-Peruchena and M. Gastón, "A simple and efficient procedure for increasing the temporal resolution of global horizontal solar irradiance series," Renew. Energy, vol. 86, pp. 375-383, Feb. 2016, doi: 10.1016/j.renene.2015.08.004.

[77] W. Zhang, W. Kleiber, A. R. Florita, B.-M. Hodge, and B. Mather, "Modeling and Simulation of High-Frequency Solar Irradiance,” IEEE J. Photovolt., vol. 9, no. 1, pp. 124-131, Jan. 2019, doi: 10.1109/JPHOTOV.2018.2879756.

[78] A. Ahmed and M. Khalid, "A review on the selected applications of forecasting models in renewable power systems," Renew. Sustain. Energy Rev., vol. 100, pp. 9-21, Feb. 2019, doi: 10.1016/j.rser.2018.09.046. 
[79] E. Cirés, J. Marcos, I. de la Parra, M. García, and L. Marroyo, "The potential of forecasting in reducing the LCOE in PV plants under ramp-rate restrictions," Energy, vol. 188, p. 116053, Dec. 2019, doi: 10.1016/j.energy.2019.116053.

[80] J. Antonanzas, N. Osorio, R. Escobar, R. Urraca, F. J. Martinez-de-Pison, and F. Antonanzas-Torres, "Review of photovoltaic power forecasting," Sol. Energy, vol. 136, pp. 78-111, Oct. 2016, doi: 10.1016/j.solener.2016.06.069.

[81] L. Vallance, "Synergie des mesures pyranométriques et des images hémisphériques in-situ avec des images satellites météorologiques pour la prévision photovoltaïque," phdthesis, PSL Research University, 2018. Accessed: Mar. 26, 2020. [Online]. Available: https://pastel.archives-ouvertes.fr/tel02097021

[82] K. Lappalainen, G. C. Wang, and J. Kleissl, "Estimation of the largest expected photovoltaic power ramp rates," Appl. Energy, vol. 278, p. 115636, Nov. 2020, doi: 10.1016/j.apenergy.2020.115636.

[83] SoDa Pro, "HelioClim-3 Real Time and Forecast - www.soda-pro.com." http://www.sodapro.com/fr/web-services/radiation/helioclim-3-real-time-and-forecast (accessed Jan. 27, 2020).

[84] M. Abuella and B. Chowdhury, "Forecasting of solar power ramp events: A post-processing approach," Renew. Energy, vol. 133, pp. 1380-1392, Apr. 2019, doi: 10.1016/j.renene.2018.09.005.

[85] P. Mathiesen, D. Rife, and C. Collier, "Forecasting solar irradiance variability using the analog method," in 2016 IEEE 43rd Photovoltaic Specialists Conference (PVSC), Jun. 2016, pp. 1207-1211. doi: 10.1109/PVSC.2016.7749806.

[86] J. Huang and R.J. Davy, "Predicting intra-hour variability of solar irradiance using hourly local weather forecasts,” Sol. Energy, vol. 139, pp. 633-639, Dec. 2016, doi: 10.1016/j.solener.2016.10.036.

[87] Y. Chu, H. T. C. Pedro, M. Li, and C. F. M. Coimbra, "Real-time forecasting of solar irradiance ramps with smart image processing," Sol. Energy, vol. 114, pp. 91-104, Apr. 2015, doi: 10.1016/j.solener.2015.01.024.

[88] C. Gauchet, P. Blanc, B. Espinar, B. Charbonnier, and D. Demengel, "Surface solar irradiance estimation with low-cost fish-eye camera,” p. 5, 2012.

[89] V. P. A. Lonij, A. E. Brooks, A. D. Cronin, M. Leuthold, and K. Koch, "Intra-hour forecasts of solar power production using measurements from a network of irradiance sensors," Sol. Energy, vol. 97, pp. 58-66, Nov. 2013, doi: 10.1016/j.solener.2013.08.002.

[90] J. L. Bosch, Y. Zheng, and J. Kleissl, "Deriving cloud velocity from an array of solar radiation measurements," Sol. Energy, vol. 87, pp. 196-203, Jan. 2013, doi: 10.1016/j.solener.2012.10.020.

[91] ETN Global, "ETN R\&D recommendation report," ETN Global, Oct. 2018. [Online]. Available: https://etn.global/research-innovation/

[92] M. L. Kubik, P. J. Coker, and J. F. Barlow, "Increasing thermal plant flexibility in a high renewables power system," Appl. Energy, vol. 154, pp. 102-111, Sep. 2015, doi: 10.1016/j.apenergy.2015.04.063.

[93] Warstila, “Combustion Engine vs Gas Turbine: Ramp Rate.” 2019. [Online]. Available: https://www.wartsila.com/energy/learn-more/technical-comparisons/combustion-engine-vs-gasturbine-ramp-rate

[94] H. I. H. Saravanamuttoo, H. Cohen, and G. F. C. Rogers, Gas turbine theory. Harlow: Prentice Hall, 2001.

[95] A. M. Y. Razak, Industrial gas turbines: performance and operability. Boca Raton, Fla.: CRC Press [u.a.], 2007.

[96] P. Jansohn, Modern gas turbine systems: high efficiency, low emission, fuel flexible power generation. 2016.

[97] Thermoflow, "Thermoflow, Inc. (Home).” https://www.thermoflow.com/ (accessed Apr. 23, 2019).

[98] E. A. EA Internacional, "EcosimPro | PROOSIS Modelling and Simulation Software," EcosimPro / PROOSIS. https://www.ecosimpro.com/ (accessed Apr. 23, 2019).

[99] F. Alobaid, N. Mertens, R. Starkloff, T. Lanz, C. Heinze, and B. Epple, "Progress in dynamic simulation of thermal power plants," Prog. Energy Combust. Sci, vol. 59, pp. 79-162, Mar. 2017, doi: 10.1016/j.pecs.2016.11.001. 
[100] A. Mehrpanahi, A. Hamidavi, and A. Ghorbanifar, "A novel dynamic modeling of an industrial gas turbine using condition monitoring data," Appl. Therm. Eng., vol. 143, pp. 507-520, Oct. 2018, doi: 10.1016/j.applthermaleng.2018.07.081.

[101] S. K. Yee, J. V. Milanovic, and F. M. Hughes, "Overview and Comparative Analysis of Gas Turbine Models for System Stability Studies,” IEEE Trans. Power Syst., vol. 23, no. 1, pp. 108-118, Feb. 2008, doi: 10.1109/TPWRS.2007.907384.

[102] E. Tsoutsanis and N. Meskin, "Dynamic performance simulation and control of gas turbines used for hybrid gas/wind energy applications," Appl. Therm. Eng., vol. 147, pp. 122-142, Jan. 2019, doi: 10.1016/j.applthermaleng.2018.09.031.

[103] A. Chaibakhsh and S. Amirkhani, "A simulation model for transient behaviour of heavy-duty gas turbines,” Appl. Therm. Eng., vol. 132, pp. 115-127, Mar. 2018, doi: 10.1016/j.applthermaleng.2017.12.077.

[104] E. Tsoutsanis, N. Meskin, M. Benammar, and K. Khorasani, "Dynamic Performance Simulation of an Aeroderivative Gas Turbine Using the Matlab Simulink Environment," in Volume 4A: Dynamics, Vibration and Control, San Diego, California, USA, Nov. 2013, p. V04AT04A050. doi: 10.1115/IMECE2013-64102.

[105] E. Tsoutsanis, M. Hamadache, and R. Dixon, "Real-Time Diagnostic Method of Gas Turbines Operating Under Transient Conditions in Hybrid Power Plants,” J. Eng. Gas Turbines Power, vol. 142, no. 10, p. 101002, Oct. 2020, doi: 10.1115/1.4048340.

[106] S. E. Turie, "Gas Turbine Plant Modeling for Dynamic Simulation," Master's Thesis, KTH School of Industrial Engineering and Management, Stockholm, Sweden, 2012.

[107] A. A. G. Pérez, "Modelling of a Gas Turbine with ModelicaTM," Master's Thesis, Lund Institute of Technology, Lund, Sweden, 2001.

[108] E. Konečná, S. Y. Teng, and V. Máša, "New insights into the potential of the gas microturbine in microgrids and industrial applications,” Renew. Sustain. Energy Rev., vol. 134, p. 110078, Dec. 2020, doi: 10.1016/j.rser.2020.110078.

[109] J. Blondeau and J. Mertens, "Impact of intermittent renewable energy production on specific CO2 and NO emissions from large scale gas-fired combined cycles," J. Clean. Prod., vol. 221, pp. 261-270, Jun. 2019, doi: 10.1016/j.jclepro.2019.02.182.

[110] G. Sujesh and S. Ramesh, "Modeling and control of diesel engines: A systematic review," Alex. Eng. J., vol. 57, no. 4, pp. 4033-4048, Dec. 2018, doi: 10.1016/j.aej.2018.02.011.

[111] L. L. J. Mahon, Diesel generator handbook. Oxford ; Boston: Butterworth-Heinemann, 1992.

[112] J. B. Heywood, Internal combustion engine fundamentals. New York: McGraw-Hill, 1988.

[113] Wartsila Finland, "Wärtsilä 32 Product guide,” p. 284, 2018.

[114] L. Guzzella and C. H. Onder, "Introduction to Modeling and Control of Internal Combustion Engine Systems," p. 362.

[115] Rakopoulos, Constantine, Giakoumis, and Evangelos, Diesel Engine Transient Operation : principles of operation and simulation analysis. Springer-Verlag London, 2009.

[116] H. Bastida, C. E. Ugalde-Loo, and M. Abeysekera, "Dynamic Modelling and Control of a Reciprocating Engine," Energy Procedia, vol. 142, pp. 1282-1287, Dec. 2017, doi: 10.1016/j.egypro.2017.12.486.

[117] A. Kuznetsov, S. Kharitonov, and V. Ryzhov, "Experimental and Calculation Study of DieselGenerator Performance in Transient Conditions," J. Eng. Gas Turbines Power, vol. 140, no. 12, p. 121009, Oct. 2018, doi: 10.1115/1.4040690.

[118] E. Semshchikov, J. Hamilton, L. Wu, M. Negnevitsky, X. Wang, and S. Lyden, "Frequency control within high renewable penetration hybrid systems adopting low load diesel methodologies," Energy Procedia, vol. 160, pp. 483-490, Feb. 2019, doi: 10.1016/j.egypro.2019.02.196.

[119] G. S. Stavrakakis and G. N. Kariniotakis, "A general simulation algorithm for the accurate assessment of isolated diesel-wind turbines systems interaction. I. A general multimachine power system model," IEEE Trans. Energy Convers., vol. 10, no. 3, pp. 577-583, Sep. 1995, doi: 10.1109/60.464885. 
[120] M. Yu, X. Tang, Y. Lin, and X. Wang, "Diesel engine modeling based on recurrent neural networks for a hardware-in-the-loop simulation system of diesel generator sets," Neurocomputing, vol. 283, pp. 9-19, Mar. 2018, doi: 10.1016/j.neucom.2017.12.054.

[121] J. Andric, D. Schimmel, A. D. Sediako, J. Sjoblom, and E. Faghani, "Development and Calibration of One Dimensional Engine Model for Hardware-In-The-Loop Applications,” p. 8, 2018.

[122] Beaulac Philippe, "Jumelage éolien-diesel avec stockage d’air comprimé," 2014.

[123] D. Nikolic, M. Negnevitsky, and M. de Groot, "Effect of the diesel engine delay on stability of isolated power systems with high levels of renewable energy penetration," in 2015 International Symposium on Smart Electric Distribution Systems and Technologies (EDST), Vienna, Austria, Sep. 2015, pp. 70-73. doi: 10.1109/SEDST.2015.7315185.

[124] J. Hamilton, M. Negnevitsky, and X. Wang, "The potential of variable speed diesel application in increasing renewable energy source penetration,” Energy Procedia, vol. 160, pp. 558-565, Feb. 2019, doi: 10.1016/j.egypro.2019.02.206.

[125] J. Hamilton, M. Negnevitsky, X. Wang, and S. Lyden, "High penetration renewable generation within Australian isolated and remote power systems," Energy, vol. 168, pp. 684-692, Feb. 2019, doi: 10.1016/j.energy.2018.11.118.

[126] J. Hamilton, A. Tavakoli, M. Negnevitsky, and X. Wang, "Investigation of no load diesel technology in isolated power systems," in 2016 IEEE Power and Energy Society General Meeting (PESGM), Boston, MA, USA, Jul. 2016, pp. 1-5. doi: 10.1109/PESGM.2016.7741324.

[127] A. Benato, S. Bracco, A. Stoppato, and A. Mirandola, "LTE: A procedure to predict power plants dynamic behaviour and components lifetime reduction during transient operation," Appl. Energy, vol. 162, pp. 880-891, Jan. 2016, doi: 10.1016/j.apenergy.2015.10.162.

[128] M. Faisal, M. A. Hannan, P. J. Ker, A. Hussain, M. B. Mansor, and F. Blaabjerg, "Review of Energy Storage System Technologies in Microgrid Applications: Issues and Challenges," IEEE Access, vol. 6, pp. 35143-35164, 2018, doi: 10.1109/ACCESS.2018.2841407.

[129] O. Krishan and S. Suhag, "An updated review of energy storage systems: Classification and applications in distributed generation power systems incorporating renewable energy resources," Int. J. Energy Res., vol. 43, no. 12, pp. 6171-6210, 2019, doi: 10.1002/er.4285.

[130] P. D. Lund, J. Lindgren, J. Mikkola, and J. Salpakari, "Review of energy system flexibility measures to enable high levels of variable renewable electricity," Renew. Sustain. Energy Rev., vol. 45, pp. 785807, May 2015, doi: 10.1016/j.rser.2015.01.057.

[131] IRENA, "Electricity storage : costs and market to 2030," Oct. 2017.

[132] Neoen Australia, "HPR fully installed and energised! - Hornsdale Power Reserve," Nov. 28, 2019. https://hornsdalepowerreserve.com.au/hpr-fully-installed-and-energised/ (accessed Apr. 28, 2020).

[133] H. Hesse, M. Schimpe, D. Kucevic, and A. Jossen, "Lithium-Ion Battery Storage for the Grid-A Review of Stationary Battery Storage System Design Tailored for Applications in Modern Power Grids,” Energies, vol. 10, no. 12, p. 2107, Dec. 2017, doi: 10.3390/en10122107.

[134] A. A. K. Arani, H. Karami, G. B. Gharehpetian, and M. S. A. Hejazi, "Review of Flywheel Energy Storage Systems structures and applications in power systems and microgrids," Renew. Sustain. Energy Rev., vol. 69, pp. 9-18, Mar. 2017, doi: 10.1016/j.rser.2016.11.166.

[135] M. A. M. Ramli, A. Hiendro, and S. Twaha, "Economic analysis of PV/diesel hybrid system with flywheel energy storage," Renew. Energy, vol. 78, pp. 398-405, Jun. 2015, doi: 10.1016/j.renene.2015.01.026.

[136] H. F. Habib, A. A. S. Mohamed, M. El Hariri, and O. A. Mohammed, "Utilizing supercapacitors for resiliency enhancements and adaptive microgrid protection against communication failures," Electr. Power Syst. Res., vol. 145, pp. 223-233, Apr. 2017, doi: 10.1016/j.epsr.2016.12.027.

[137] U. Akram, M. Khalid, and S. Shafiq, "An Innovative Hybrid Wind-Solar and Battery-Supercapacitor Microgrid System-Development and Optimization,” IEEE Access, vol. 5, pp. 25897-25912, 2017, doi: 10.1109/ACCESS.2017.2767618. 
[138] E. Mohammadi, R. Rasoulinezhad, and G. Moschopoulos, "Using a Supercapacitor to Mitigate Battery Microcycles Due to Wind Shear and Tower Shadow Effects in Wind-Diesel Microgrids," IEEE Trans. Smart Grid, vol. 11, no. 5, pp. 3677-3689, Sep. 2020, doi: 10.1109/TSG.2020.2979140.

[139] B. Meyer, M. Jerosolimski, and M. Stubbe, "Outils de simulation dynamique des réseaux électriques," Tech. Ing. Réseaux Électr. Transp. Répart, vol. base documentaire : TIB263DUO., no. ref. article : d4120, 1998, [Online]. Available: https://www.techniques-ingenieur.fr/base-documentaire/energiesth4/reseaux-electriques-de-transport-et-de-repartition-42263210/outils-de-simulation-dynamique-desreseaux-electriques-d4120/

[140] P. S. Kundur, Power system stability and control, Indian edition. Mc Graw Hill Education (India) Private Limited, 1994.

[141] The shift project, "Power Systems 2050 - Power System operation V1.1.” Feb. 2020.

[142] IRENA, Planning for the renewable future: Long-term modelling and tools to expand variable renewable power in emerging economies. Abu Dhabi: International Renewable Energy Agency (IRENA), 2017. Accessed: May 11, 2020. [Online]. Available: http://www.irena.org/DocumentDownloads/Publications/IRENA_REthinking_Energy_2017.pdf

[143] J.-L. Fraisse and L. Karsenti, "Raccordement de la production décentralisée aux réseaux de distribution - Conditions d'intégration," p. 41, 2014.

[144] F. M. Uriarte, C. Smith, S. VanBroekhoven, and R. E. Hebner, "Microgrid Ramp Rates and the Inertial Stability Margin,” IEEE Trans. Power Syst., vol. 30, no. 6, pp. 3209-3216, Nov. 2015, doi: 10.1109/TPWRS.2014.2387700.

[145] N. Soni, S. Doolla, and M. C. Chandorkar, "Improvement of Transient Response in Microgrids Using Virtual Inertia," IEEE Trans. Power Deliv., vol. 28, no. 3, pp. 1830-1838, Jul. 2013, doi: 10.1109/TPWRD.2013.2264738.

[146] F. Katiraei and M. R. Iravani, "Power Management Strategies for a Microgrid With Multiple Distributed Generation Units," IEEE Trans. Power Syst., vol. 21, no. 4, pp. 1821-1831, Nov. 2006, doi: 10.1109/TPWRS.2006.879260.

[147] J. M. Guerrero, J. C. Vasquez, J. Matas, L. G. de Vicuna, and M. Castilla, "Hierarchical Control of Droop-Controlled AC and DC Microgrids-A General Approach Toward Standardization,” IEEE Trans. Ind. Electron., vol. 58, no. 1, pp. 158-172, Jan. 2011, doi: 10.1109/TIE.2010.2066534.

[148] C. C. Arteaga, "Optimisation of power system security with high share of variable renewables: Consideration of the primary reserve deployment dynamics on a Frequency Constrained Unit Commitment model,” Thèse de doctorat, Univertié Paris-Saclay, Paris, France, 2016.

[149] T. Morstyn, B. Hredzak, and V. G. Agelidis, "Control Strategies for Microgrids With Distributed Energy Storage Systems: An Overview,” IEEE Trans. Smart Grid, vol. 9, no. 4, pp. 3652-3666, Jul. 2018, doi: 10.1109/TSG.2016.2637958.

[150] J. Li, R. Xiong, Q. Yang, F. Liang, M. Zhang, and W. Yuan, "Design/test of a hybrid energy storage system for primary frequency control using a dynamic droop method in an isolated microgrid power system,” Appl. Energy, vol. 201, pp. 257-269, Sep. 2017, doi: 10.1016/j.apenergy.2016.10.066.

[151] I. Serban and C. Marinescu, "Control Strategy of Three-Phase Battery Energy Storage Systems for Frequency Support in Microgrids and with Uninterrupted Supply of Local Loads," IEEE Trans. Power Electron., vol. 29, no. 9, pp. 5010-5020, Sep. 2014, doi: 10.1109/TPEL.2013.2283298.

[152] M. Toge, Y. Kurita, and S. Iwamoto, "Supplementary load frequency control with storage battery operation considering SOC under large-scale wind power penetration," in 2013 IEEE Power \& Energy Society General Meeting, Vancouver, BC, 2013, pp. 1-5. doi: 10.1109/PESMG.2013.6672323.

[153] G. O. Suvire, M. G. Molina, and P. E. Mercado, "Improving the Integration of Wind Power Generation Into AC Microgrids Using Flywheel Energy Storage," IEEE Trans. Smart Grid, vol. 3, no. 4, pp. 1945-1954, Dec. 2012, doi: 10.1109/TSG.2012.2208769.

[154] C. Abbey and G. Joos, "Supercapacitor Energy Storage for Wind Energy Applications," IEEE Trans. Ind. Appl., vol. 43, no. 3, pp. 769-776, May 2007, doi: 10.1109/TIA.2007.895768. 
[155] W. Gu, W. Liu, C. Shen, and Z. Wu, "Multi-stage underfrequency load shedding for islanded microgrid with equivalent inertia constant analysis," Int.J. Electr. Power Energy Syst., vol. 46, pp. 3639, Mar. 2013, doi: 10.1016/j.jjepes.2012.10.003.

[156] M. Hajiakbari Fini and M. E. Hamedani Golshan, "Frequency control using loads and generators capacity in power systems with a high penetration of renewables," Electr. Power Syst. Res., vol. 166, pp. 43-51, Jan. 2019, doi: 10.1016/j.epsr.2018.09.010.

[157] A. Arif, Z. Wang, J. Wang, B. Mather, H. Bashualdo, and D. Zhao, "Load Modeling-A Review," IEEE Trans. Smart Grid, vol. 9, no. 6, pp. 5986-5999, Nov. 2018, doi: 10.1109/TSG.2017.2700436.

[158] M. Dreidy, H. Mokhlis, and S. Mekhilef, "Inertia response and frequency control techniques for renewable energy sources: A review,” Renew. Sustain. Energy Rev., vol. 69, pp. 144-155, Mar. 2017, doi: 10.1016/j.rser.2016.11.170.

[159] A. Hoke and D. Maksimović, "Active power control of photovoltaic power systems," in 2013 1st IEEE Conference on Technologies for Sustainability (SusTech), Aug. 2013, pp. 70-77. doi: 10.1109/SusTech.2013.6617300.

[160] G. Dickeson, L. McLeod, A. Dobb, L. Frearson, B. Herteleer, and D. Scheltus, "RAMP RATE CONTROL FOR PV PLANT INTEGRATION: EXPERIENCE FROM KARRATHA AIRPORT'S HYBRID POWER STATION,” p. 6.

[161] J. Matevosyan et al., "Grid-Forming Inverters: Are They the Key for High Renewable Penetration?," IEEE Power Energy Mag., vol. 17, no. 6, pp. 89-98, Nov. 2019, doi: 10.1109/MPE.2019.2933072.

[162] S. Sasmono, J. A. Chandra, A. Wijaya, and N. Hariyanto, "Transient Stability Method to Determine Maximum Intermittent Power Plant Penetration to Small Island Isolated System," in 2018 IEEE PES Asia-Pacific Power and Energy Engineering Conference (APPEEC), Kota Kinabalu, Oct. 2018, pp. 498-501. doi: 10.1109/APPEEC.2018.8566468.

[163] R. Rossi and M. A. S. Masoum, "Application of swing equation and equal area criteria to determine maximum penetration of wind generation in an islanded network," in 2013 Australasian Universities Power Engineering Conference (AUPEC), Hobart, Australia, Sep. 2013, pp. 1-8. doi: 10.1109/AUPEC.2013.6725387.

[164] M. C. Magro, M. Giannettoni, P. Pinceti, and M. Vanti, "Real time simulator for microgrids," Electr. Power Syst. Res., vol. 160, pp. 381-396, Jul. 2018, doi: 10.1016/j.epsr.2018.03.018.

[165] L. Polleux, J. Sandoval-Moreno, G. Guerassimoff, and J.-P. Marmorat, "Impact of thermal generation flexibility on power quality and LCOE of industrial off-grid power plants," in Proceedings of 11th International Conference on Applied Energy, Part 2, Västeraas, Sweden, Aug. 2019, vol. 3.

[166] A. Mohammed, J. Pasupuleti, T. Khatib, and W. Elmenreich, "A review of process and operational system control of hybrid photovoltaic/diesel generator systems," Renew. Sustain. Energy Rev., vol. 44, pp. 436-446, Apr. 2015, doi: 10.1016/j.rser.2014.12.035.

[167] H. Kanchev, D. Lu, F. Colas, V. Lazarov, and B. Francois, "Energy Management and Operational Planning of a Microgrid With a PV-Based Active Generator for Smart Grid Applications," IEEE Trans. Ind. Electron., vol. 58, no. 10, pp. 4583-4592, Oct. 2011, doi: 10.1109/TIE.2011.2119451.

[168] A. Chaouachi, R. M. Kamel, R. Andoulsi, and K. Nagasaka, "Multiobjective Intelligent Energy Management for a Microgrid,” IEEE Trans. Ind. Electron., vol. 60, no. 4, pp. 1688-1699, Apr. 2013, doi: 10.1109/TIE.2012.2188873.

[169] T. Wang, X. He, and T. Deng, "Neural networks for power management optimal strategy in hybrid microgrid,” Neural Comput. Appl., vol. 31, no. 7, pp. 2635-2647, Jul. 2019, doi: 10.1007/s00521017-3219-x.

[170] A. Askarzadeh, "A Memory-Based Genetic Algorithm for Optimization of Power Generation in a Microgrid,” IEEE Trans. Sustain. Energy, vol. 9, no. 3, pp. 1081-1089, Jul. 2018, doi: 10.1109/TSTE.2017.2765483.

[171] A. Maulik and D. Das, "Optimal operation of microgrid using four different optimization techniques," Sustain. Energy Technol. Assess., vol. 21, pp. 100-120, Jun. 2017, doi: 10.1016/j.seta.2017.04.005. 
[172] M. Marzband, F. Azarinejadian, M. Savaghebi, and J. M. Guerrero, “An Optimal Energy Management System for Islanded Microgrids Based on Multiperiod Artificial Bee Colony Combined With Markov Chain,” IEEE Syst.J., vol. 11, no. 3, pp. 1712-1722, Sep. 2017, doi: 10.1109/JSYST.2015.2422253.

[173] C. Ju, P. Wang, L. Goel, and Y. Xu, "A Two-Layer Energy Management System for Microgrids With Hybrid Energy Storage Considering Degradation Costs," IEEE Trans. Smart Grid, vol. 9, no. 6, pp. 6047-6057, Nov. 2018, doi: 10.1109/TSG.2017.2703126.

[174] J. D. Lara, D. E. Olivares, and C. A. Cañizares, "Robust Energy Management of Isolated Microgrids," IEEE Syst.J., vol. 13, no. 1, pp. 680-691, Mar. 2019, doi: 10.1109/JSYST.2018.2828838.

[175] M. Mohiti, M. Mazidi, A. A. Moghaddam, and J. M. Guerrero, "Microgrid optimal energy and reserve scheduling considering frequency constraints," in 2019 International Conference on Smart Energy Systems and Technologies (SEST), Sep. 2019, pp. 1-6. doi: 10.1109/SEST.2019.8849072.

[176] A. N'Goran, B. Daugrois, M. Lotteau, and S. Demassey, "Optimal engagement and operation of a grid-connected PV/battery system," in 2019 IEEE PES Innovative Smart Grid Technologies Europe (ISGT-Europe), Sep. 2019, pp. 1-5. doi: 10.1109/ISGTEurope.2019.8905617.

[177] D. E. Olivares, C. A. Canizares, and M. Kazerani, "A Centralized Energy Management System for Isolated Microgrids," IEEE Trans. Smart Grid, vol. 5, no. 4, pp. 1864-1875, Jul. 2014, doi: 10.1109/TSG.2013.2294187.

[178] R. Palma-Behnke et al., "A Microgrid Energy Management System Based on the Rolling Horizon Strategy,” IEEE Trans. Smart Grid, vol. 4, no. 2, pp. 996-1006, Jun. 2013, doi: 10.1109/TSG.2012.2231440.

[179] N. Rezaei and M. Kalantar, "Economic-environmental hierarchical frequency management of a droop-controlled islanded microgrid," Energy Convers. Manag., vol. 88, pp. 498-515, Dec. 2014, doi: 10.1016/j.enconman.2014.08.054.

[180] S. Cominesi, M. Farina, L. Giulioni, B. Picasso, and R. Scattolini, "A Two-Layer Stochastic Model Predictive Control Scheme for Microgrids," IEEE Trans. Control Syst. Technol., vol. 26, no. 1, pp. 1-13, Jan. 2018, doi: 10.1109/TCST.2017.2657606.

[181] S. R. Cominesi, A. L. Bella, M. Farina, and R. Scattolini, "A multi-layer control scheme for microgrid energy management,” IFAC-Pap., vol. 49, no. 27, pp. 256-261, 2016, doi: 10.1016/j.ifacol.2016.10.700.

[182] J. Hu, Y. Shan, J. M. Guerrero, A. Ioinovici, K. W. Chan, and J. Rodriguez, "Model predictive control of microgrids - An overview," Renew. Sustain. Energy Rev., vol. 136, p. 110422, Feb. 2021, doi: 10.1016/j.rser.2020.110422.

[183] E. Mayhorn, W. Zhang, S. Lu, and N. Samaan, "Optimal Control of Distributed Energy Resources using Model Predictive Control," IEEE Power Energy Soc. Gen. Meet., p. 8, 2012, doi: 10.1109/PESGM.2012.6345596.

[184] L. Moretti, S. Polimeni, L. Meraldi, P. Raboni, S. Leva, and G. Manzolini, "Assessing the impact of a two-layer predictive dispatch algorithm on design and operation of off-grid hybrid microgrids," Renew. Energy, vol. 143, pp. 1439-1453, Dec. 2019, doi: 10.1016/j.renene.2019.05.060.

[185] B. Wang, "Intelligent control and power flow optimization of microgrid," Université de Technologie de Compiègne, $2013 . \quad$ [Online]. Available: https://pdfs.semanticscholar.org/b2ad/6d61acfceef1969a484f0d895b321f416a0e.pdf

[186] V. Krakowski, "Intégration du renouvelable et stratégie de déploiement du réseau électrique: réconciliation d'échelles spatio-temporelles dans des exercices prospectifs de long terme," Paris Sciences et Lettres, 2016.

[187] M. Drouineau, N. Maïzi, and V. Mazauric, "Impacts of intermittent sources on the quality of power supply: The key role of reliability indicators," Appl. Energy, vol. 116, pp. 333-343, Mar. 2014, doi: 10.1016/j.apenergy.2013.11.069.

[188] R. Rigo-Mariani, B. Sareni, and X. Roboam, "Integrated Optimal Design of a Smart Microgrid With Storage," IEEE Trans. Smart Grid, vol. 8, no. 4, pp. 1762-1770, Jul. 2017, doi: 10.1109/TSG.2015.2507131. 
[189] T. Schittekatte, M. Stadler, G. Cardoso, S. Mashayekh, and N. Sankar, "The Impact of Short-Term Stochastic Variability in Solar Irradiance on Optimal Microgrid Design," IEEE Trans. Smart Grid, vol. 9, no. 3, pp. 1647-1656, May 2018, doi: 10.1109/TSG.2016.2596709.

[190] A. Khodaei, S. Bahramirad, and M. Shahidehpour, "Microgrid Planning Under Uncertainty," IEEE Trans. Power Syst., vol. 30, no. 5, pp. 2417-2425, Sep. 2015, doi: 10.1109/TPWRS.2014.2361094.

[191] A. Billionnet, M.-C. Costa, and P.-L. Poirion, "Robust optimal sizing of a hybrid energy stand-alone system,” Eur.J. Oper. Res., vol. 254, no. 2, pp. 565-575, Oct. 2016, doi: 10.1016/j.ejor.2016.03.013.

[192] S. Chalil Madathil et al., "Resilient Off-Grid Microgrids: Capacity Planning and N-1 Security," IEEE Trans. Smart Grid, vol. 9, no. 6, pp. 6511-6521, Nov. 2018, doi: 10.1109/TSG.2017.2715074. 